\title{
Game Over?
}

\section{Adolescent gambling behaviour after interventions in the gambling market - a public health perspective}

Marianne Bang Hansen

Department of Psychology

Faculty of Social Sciences

University of Oslo

and

The Norwegian Institute of Alcohol and Drug Research, SIRUS

Oslo 2011 


\section{(C) Marianne Bang Hansen, 2012}

\section{Series of dissertations submitted to the \\ Faculty of Social Sciences, University of Oslo}

No. 325

ISSN 1504-3991

All rights reserved. No part of this publication may be

reproduced or transmitted, in any form or by any means, without permission.

Cover: Inger Sandved Anfinsen.

Printed in Norway: AIT Oslo AS.

Produced in co-operation with Unipub, Oslo.

The thesis is produced by Unipub merely in connection with the thesis defence. Kindly direct all inquiries regarding the thesis to the copyright holder or the unit which grants the doctorate. 
"...the deviants are simply the tail of the population's own distribution; they

belong to each other and society is one, whether it likes it or not" (Rose 1985). 



\section{Content}

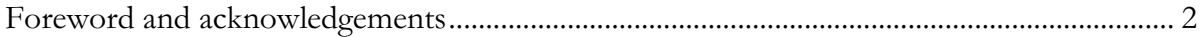

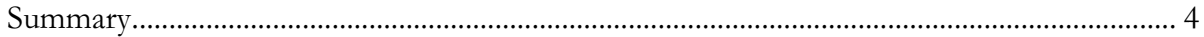

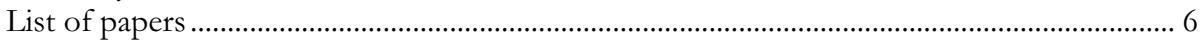

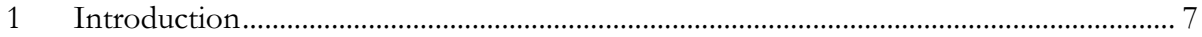

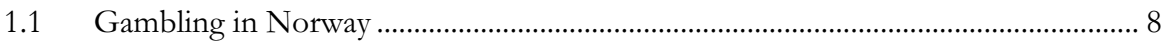

1.2 Definition of gambling and problem gambling …………....................................... 9

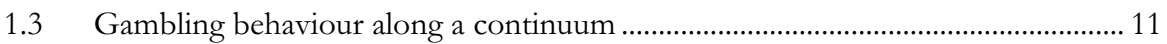

1.4 Gambling behaviour among adolescents .................................................................. 12

1.5 The aetiology and maintenance of gambling behaviour and problem gambling.. 14

1.6 Gambling behaviour - from individual to aggregated levels of understanding .... 18

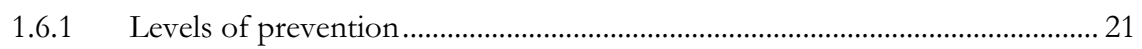

1.6.2 Adolescent gambling from a public health perspective.................................... 21

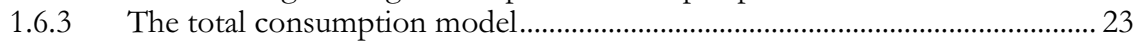

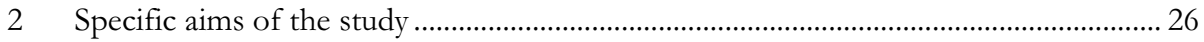

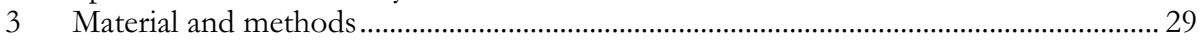

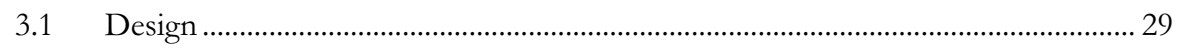

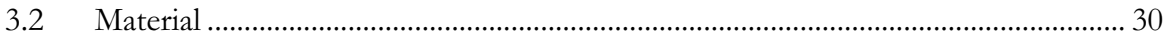

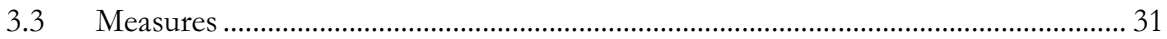

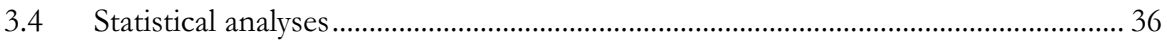

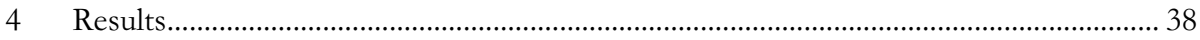

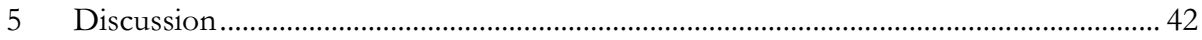

5.1 The total consumption model and adolescent gambling behaviour........................ 44

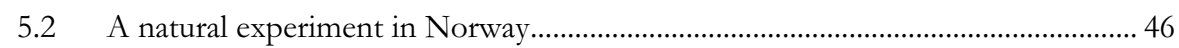

5.3 Contradictory findings - challenges in evaluating policy measures .......................... 48

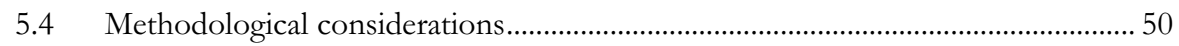

5.5 Strengths and limitations of these studies................................................................. 52

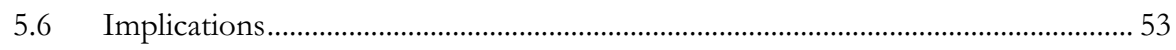

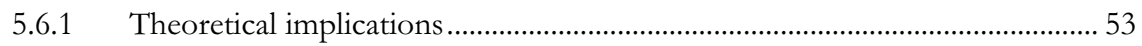

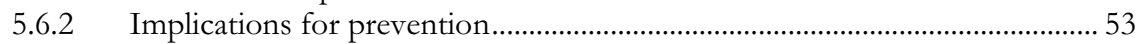

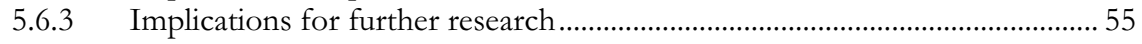

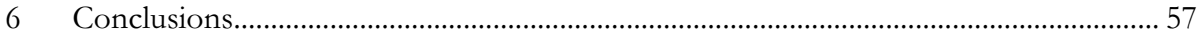

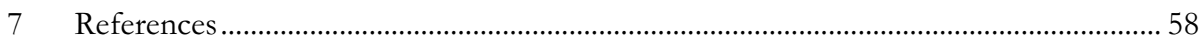




\section{Foreword and acknowledgements}

The point of departure for this thesis has changed underway. In 2003, the Norwegian authorities decided to introduce a monopoly for running slot machines. The proposal was to ban slot machines as they then were, owned by a series of private organizations and several large voluntary organizations, such as the Red Cross and Norwegian Sea Rescue. The introduction of a monopoly would mean that the only organization that could run slot machines was the state-owned company Norsk Tipping, and that the profit from this company would be distributed to a number of voluntary organizations. This was opposed, among others, by the private slot machine industry, that brought an action against the state in the EFTA court and in the Norwegian court. The introduction of a slot machine monopoly was postponed, and while we waited for the judgement, it was decided that a ban on the use of banknote acceptors in slot machines should be introduced in 2006. In 2005, the Norwegian state was given support for its decision, both in the EFTA court and in the Norwegian Supreme Court. Therefore, the next year, in 2007 , the market was monopolized, with a ban on all existing slot machines from 1 July 2007.

The application for this thesis was written in 2004, based on the original plan for the changes to the slot machine market. The data collection for the project was carried out as planned, since this was part of the data collection for another large project (the Regional Project) that would go its course independently of when and how the slot machine market would be altered. In other words, the interventions were very delayed in relation to the original plan. It also became apparent that collecting two sets of data before anything happened to the slot machine market was fortunate, since they could function as controls for sets of data that were collected later. So even though the field changed underway, we managed to ensure a good design for the research questions we wanted to investigate. This is a good example of how it can be to carry out research in the real-life situation.

Work with this thesis has been carried out at the Norwegian Institute for Alcohol and Drug Research (SIRUS). The research has mainly been funded by the Research Council of Norway, with funding for the last few months from SIRUS. 
Several people have contributed to the thesis. The person who deserves the most thanks is Ingeborg Rossow, who has been my main supervisor for this doctoral project. Ingeborg is also co-author for all articles in this thesis. I have benefitted a lot from her dependability, generosity, skills and care during all of this work, and I have learnt a lot from her. Thanks also to Jostein Rise, who has been my co-supervisor, and who has given me a lot of valuable and useful support, inspiration and help with the summary. A big thanks to Elisabet Storvoll, research leader at SIRUS, co-author for one of the articles, and a dear friend, colleague and training companion. She has given me a lot of important motivation and encouragement on the treadmill in the cellar in SIRUS.

A big thanks to my colleague Elisabeth Larsen, whose door has always been open, and who has been available to listen to me, to Elin Bye, who manages to fix most things and to come out the other end, to Ellen Amundsen, who with wisdom and insight discusses every question about methodology, to Astrid Skatvedt, who has ensured that I have been nourished underway, and to Tord Finne Vedøy, who fixes deadlocked diagrams. In addition, thanks to everyone in the library of SIRUS for supreme service and prompt help.

I also wish to thank all my other colleagues and friends at SIRUS, particularly those on level 6b, including Janne Scheffels. It has been a good place to be and a good environment to work in.

Finally, thanks to Geir, who has given me encouragement, supported me, and allowed me the space to carry out this work. He has made a constructive contribution by reading through the thesis in the final stages.

Oslo, November 2011

Marianne Bang Hansen 


\section{Summary}

The Norwegian gambling market grew tremendously in the period from the late 1980s until 2005. The negative consequences of gambling, especially among young people, have received increasing attention in our society. In 2006 and 2007 a natural experiment took place in the Norwegian slot machine market. Banknote acceptors in slot machines were first prohibited in 2006, and all slot machines were removed one year later.

Knowledge about how structural changes like this affect behaviour was lacking. The intervention in the slot machine gambling market was a unique opportunity to obtain a better empirical basis for the legitimacy of population-based interventions.

The overall aim of this thesis was to assess the empirical basis for the appropriateness of population strategies in curbing problem gambling and furthermore to assess whether the regulations in the Norwegian slot machine market had any impact on gambling and problem gambling among adolescents.

This thesis comprises four articles and an overall summary. The data were collected by school surveys carried out in 2002, 2004, 2005, 2006, and 2008. The target population in all the surveys was students from lower and upper secondary schools.

A close relationship between the overall amount of gambling and the proportion of problem gamblers in a population was observed, and further, a reduction in the overall amount of gambling among adolescents was accompanied by a collective downward shift in all groups of gamblers, i.e. among excessive gamblers as well as among moderate and light gamblers.

After the two interventions in 2006 and 2007, significant decreases were observed in overall gambling. However, the prevalence of problem gambling did not show the same systematic trends. Thus, this discrepancy in trends between problem gambling and gambling behaviour suggests that the observed changes may not only be interpreted as intervention effects, but may also be attributed to other significant changes in the gambling market. 
The findings represent a clear parallel to the alcohol field, and thus provide empirical support for a total consumption model of gambling behaviour among adolescents. The discrepancies in the consumption of gambling and gambling-related harm points out some important methodological challenges in the assessment of gambling behaviour in a rapidly changing gambling market.

The findings of this thesis have several implications. Prevention strategies directed at the total population of gamblers seem highly relevant, as a reduction in overall gambling is related to the level of gambling problems among youths, and thus, policy measures and structural interventions can serve as effective preventive measures. 


\section{List of papers}

Hansen, M., \& Rossow, I. (2008). Adolescent gambling and problem gambling: Does the total consumption model apply? Journal of Gambling Studies, 24, 135-149.

Hansen, M., \& Rossow, I. (2010). Limited cash flow on slot machines: Effects of prohibition of note acceptors on adolescent gambling behavior. International Journal of Mental Health and Addiction. DOI 10.1007/s11469-009-9196-2

Hansen, M., \& Rossow, I. (2011). Does a reduction in the overall amount of gambling imply a reduction at all levels of gambling? Addiction Research and Theory, in press

Rossow, I., Hansen, M. B., \& Storvoll, E. (submitted). Evaluating impact of national restrictions on availability of gambling: Challenges in evaluating impact of national restrictions on gambling availability - The Norwegian experience. Journal of Gambling Studies 


\section{Introduction}

In this thesis, I present how and in which way the level of gambling in the population has an influence on the gambling behaviour of young Norwegians, and whether and to what extent structural changes in the slot machine gambling market might impact on gambling and problems caused by gambling in the youth population. Gambling implies games played for money in the traditional sense - games where people stake money and in which the outcome of the game is wholly or partly based on chance.

The negative consequences of slot machine gambling can be reduced to an individual problem, in which the individual's vulnerability and choices are decisive for whether he or she develops a gambling problem. From such a perspective, perhaps it does not really matter how the gambling market is regulated, while availability of adequate treatment becomes all the more important. Another perspective is that problem gambling can be regarded as a public health problem for which responsibility for prevention lies at the community level in the form of politically-managed regulation. Regulation of the Norwegian slot machine market is an example of prevention at such an overall level, in which structural changes have been made in the Norwegian slot machine market with the aim of limiting slot machine gambling behaviour.

Research about what can contribute to effective prevention of gambling problems has been called for. In this thesis, I begin with a natural experiment, which took place in the slot machine market in Norway in the period 2004 to 2007, when use of banknote acceptors in slot machines was forbidden from 1 July 2006, and all slot machines were forbidden and removed twelve months later. These two measures represent a unique type of regulation that has not previously taken place any other place in the world.

The theoretical approach for the thesis is based on the total consumption model and a public health perspective of gambling and problem gambling. An important premise for the thesis is that when total use of gambling among young people increases, then the level of problem gambling in the population of young people will also increase. This is well documented for alcohol in several studies. It is interesting to examine whether this is also valid for gambling, because, if this is the case, it will have important implications for how problem gambling can be prevented in the population. 
I begin with a brief description of gambling in Norway. I then describe gambling behaviour and gambling problems, how widespread these are, and how they can be understood from a psychological perspective. I then go further to relate this to a more overall public health perspective, and in this way highlight the importance of including a public health perspective in relation to mental health. This is illustrated by describing how gambling and gambling problems in the population of young people can be influenced by overall structural interventions.

\subsection{Gambling in Norway}

Today, revenue from gambling serves as an important financial source for voluntary organizations, humanitarian work and sports activities. The regulation of gambling markets has gone through a process of liberalization during the last twenty-five years and the commercialization of gambling has increased accordingly. Despite this, gambling is prohibited in Norway by law. All forms of gambling allowed in Norway are exceptions from the law, and lotteries can only be held if the profit goes to humanitarian or public utility purposes (Lotteries Act Sections 5 and 6). The Norwegian gambling market is organized as a monopoly with two actors; one for horse racing and one for sports betting and lotto. In addition, organizations like the Red Cross, Norwegian Sea Rescue and the Norwegian Cancer Society, have had permission to operate slot machines as a source of financing their humanitarian and voluntary work. At the end of the 1980s, a deregulation occurred in the slot machine market, which meant that anyone could set up their own slot machine business if a percentage of the turnover was given to a worthy cause. There were no restrictions on age or placement of the machines and they soon became easily available in grocery stores, petrol stations, bus terminals and train stations. The slot machine market increased enormously. From 1999 to 2005, the annual turnover on slot machines increased from NOK 190 million to NOK 30000 million. Concurrent with the increase in the slot machine market, several treatment centres reported an increase in people seeking help for their gambling problems (Fekjær 2001; Hansen and Skjerve 2006). An awareness of the possible negative consequences of slot machine gambling emerged both among politicians and the general public, resulting in measures to prevent problem gambling in the population. 
In 2003, the Norwegian Government made a resolution to prohibit all existing slot machines and to establish a state monopoly of slot machines with the purpose of both ensuring revenue to humanitarian purposes, and preventing and reducing gamblingrelated harm. From 1 July 2006, banknote acceptors on all slot-machines were prohibited. One year later, in July 2007, all slot machines were prohibited. In other words, from one year to the next, major changes occurred in the Norwegian gambling market. These measures provided a rare opportunity to explore whether and to what extent structural changes in the gambling market influenced gambling behaviour in general among Norwegian adolescents, and more specifically, how the consumption of gambling and levels of problem gambling developed during and after the measures were introduced.

\subsection{Definition of gambling and problem gambling}

A variety of terms are used to refer to the difficulties caused by a person's gambling. The term pathological gambling is usually used to describe the small minority of problem gamblers at the far end of a continuum of gambling problems (Volberg 2003), but terms like problem gambling, gambling-related problems, at-risk gambling, excessive gambling, gambling problems and even maladaptive gambling also refer to the same phenomenon, and are used interchangeably in the gambling literature. In this thesis, I mainly use the terms problem gambling, gambling problems, and at-risk gambling when referring to the phenomenon.

Pathological gambling is defined as an impulse control disorder in the classification systems DSM (Diagnostic and Statistical Manual of Mental Disorders)(American Psychiatric Association 2000) and ICD (International Classification of Diseases) (WHO 2009), but is also called a behavioural addiction or an addiction without a drug (Potenza, Steinberg et al. 2006). Gambling differs from other addictive activities like drinking alcohol and smoking tobacco because nothing is introduced into the body and the disorder cannot be seen or smelled. Nevertheless, in the worst cases, the consequences for the gambler and his or her environment are at least as serious as for other forms of addiction.

Among so-called excessive behaviours (e.g. eating, sex, shopping), pathological gambling is the only one with a diagnosis in DSM (Petry 2006). Pathological gambling 
is conceptualized as a preoccupation with gambling, a lack of adequate control over one's behaviour, and an inability to stop playing in spite of one's desire to do so (American Psychiatric Association 2000). The American Psychiatric Association (2000) further defines pathological gambling as "persistent and recurrent maladaptive gambling behavior that disrupts personal, family, or vocational pursuits". The DSM-IV criteria for pathological gambling consist of ten criteria, equally weighted to assess gambling problems.

Table 1. DSM-IV Criteria for Pathological Gambling (American Psychiatric Association 2000)

\begin{tabular}{|c|c|}
\hline Behaviour & Description \\
\hline Preoccupation & $\begin{array}{l}\text { Is preoccupied with gambling (e.g., preoccupied with reliving past } \\
\text { gambling experiences, handicapping or planning the next venture, } \\
\text { or thinking of ways to get money with which to gamble) }\end{array}$ \\
\hline Tolerance & $\begin{array}{l}\text { Needs to gamble with increasing amounts of money in order to } \\
\text { achieve the desired excitement }\end{array}$ \\
\hline Withdrawal & $\begin{array}{l}\text { Is restless or irritable when attempting to cut down or stop } \\
\text { gambling }\end{array}$ \\
\hline Escape & $\begin{array}{l}\text { Gambles as a way of escaping from problems or relieving } \\
\text { dysphoric mood (e.g., feelings of helplessness, guilt, anxiety or } \\
\text { depression) }\end{array}$ \\
\hline Chasing & $\begin{array}{l}\text { After losing money gambling, often returns another day in order } \\
\text { to win back the losses ('chasing one's losses') }\end{array}$ \\
\hline Lying & $\begin{array}{l}\text { Lies to family members, therapist or others to conceal the extent } \\
\text { of involvement with gambling }\end{array}$ \\
\hline Loss of control & $\begin{array}{l}\text { Has made repeated unsuccessful efforts to control, cut back or } \\
\text { stop gambling }\end{array}$ \\
\hline Illegal acts & $\begin{array}{l}\text { Has committed illegal acts (e.g. forgery, fraud, theft or } \\
\text { embezzlement) in order to finance gambling }\end{array}$ \\
\hline $\begin{array}{l}\text { Risked } \\
\text { significant } \\
\text { relationship }\end{array}$ & $\begin{array}{l}\text { Has jeopardized or lost a significant relationship, job or } \\
\text { educational or career opportunity because of gambling }\end{array}$ \\
\hline Bailout & $\begin{array}{l}\text { Has relied on others to provide money to relieve a desperate } \\
\text { financial situation caused by gambling }\end{array}$ \\
\hline
\end{tabular}


An adult person exhibiting five or more of the criteria above is considered to be a pathological gambler. Pathological gambling was included in the DSM nomenclature in 1980 (American Psychiatric Association 1980) as an impulse control disorder. One of the most applied instruments on adolescent gambling - the South Oaks Gambling Screen - Revised for Adolescents, is based on the DSM nomenclature. There are overlapping definitions between pathological gambling as an impulse control disorder and a disorder with strong elements of addiction. In previous editions of the DSM, pathological gambling was classified in the section "Impulse-Control Disorders Not Elsewhere Classified". In the fifth edition, the Substance Use Disorders Workgroup of the APA's DSM committee suggested moving pathological gambling to the chapter associated with drug and alcohol use disorders (Petry 2010).

\subsection{Gambling behaviour along a continuum}

The DSM criteria for at-risk and pathological gambling give a clear cut-off between pathological gamblers and other gamblers. Gambling behaviour can also be conceptualized along a continuum ranging from non-gambling to pathological gambling (Derevensky \& Gupta 2007 in Smith, Hodgins \& Williams 2007). The continuum has no fixed cut-off between those with and those without gambling problems, but rather a more gliding transition. In line with this, it has been argued that there is no such thing as maladaptive gambling; there is only gambling (Dickerson and O'Connor 2006), and pathological gambling is conceptually perceived as an end-point on a continuum of gambling involvement (Blaszczynski and Nower 2002).

Figure 1. Gambling behaviour along a continuum

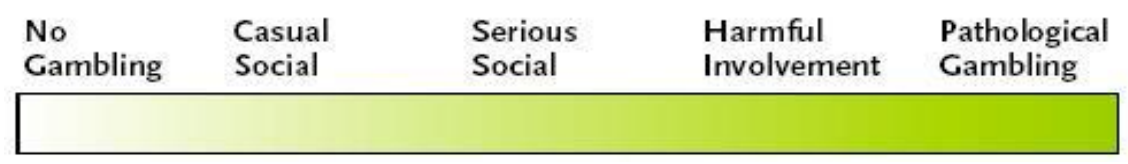

Some people never gamble, but the majority of people in most societies where gambling is allowed and available gamble casually now and then. For some people gambling is a central activity in their lives, but not necessarily the most important activity. A small group of people experience their gambling to be harmful and to create difficulties in 
their personal work and social relationships, and a small but significant minority, experience loss of control and major problems related to their gambling habits.

Gambling behaviour in general and problem gambling in particular are facilitated, maintained and accompanied by a whole range of complex factors. I will come back to some of these factors later. A continuous perspective of gambling can help us to keep in mind that problem gambling behaviour is related to gliding transitions between socalled normality and deviance, and not a kind of weakness in the individual. Therefore, the increase in gambling both nationally and internationally is a matter of concern in the understanding of gambling behaviour, as the trends in at-risk and problem gambling have been upwards over the last decades. The prevalence of at-risk and problem gambling varies from country to country. Among other things, this is due to factors such as gambling policy and regulation, type of gambling available and how gambling behaviour and problem gambling are measured.

\subsection{Gambling behaviour among adolescents}

The current youth generation grows up in a society where gambling is - more or less allowed, accepted and available. Adolescence is a vulnerable period in the sense that it is a transition period and a period of formation where an important basis for adult life is built. Gambling during adolescence is also symptomatic for how adolescents more frequently engage in novel and potentially dangerous activities (Proimos, DuRant et al. 1998; Romer 2003). However, gambling behaviour often begins earlier than other potentially addictive behaviours such as smoking and alcohol use (Gupta \& Derevensky 2006).

From a cognitive and neurological perspective, it is known that the adolescent brain is immature and neurological structures underlying the more complex and reflective cognitions of importance for self-regulation are not fully developed until the early twenties (Metcalfe and Mischel 1999; Chambers, Taylor et al. 2003; Mischel and Ayduk 2004). Further, it has been argued that adolescents are especially vulnerable to the negative consequences of gambling because 'addictive features' and easy access make gambling easy to start and more difficult to end (Griffiths 1993; Griffiths 1995; Hardoon and Derevensky 2002; Derevensky and Gupta 2004). Little is known about the antecedents of youth problem gambling (Stinchfield 2004), but research indicates that gambling behaviour may be established early with rapid movement from social gambler 
to problem gambler (Gupta and Derevensky 2000; Rossow and Hansen 2003), and it is well documented that early involvement in gambling is predictive of later gambling problems (Volberg 1993).

Gambling for money is usually viewed as an activity for adults and includes a variety of activities in different settings, from traditional land-based games purchased from gambling distributors, casinos, slot machines and bingos, to internet-based games. However, young people are involved in a variety of forms of gambling (Derevensky, Shek et al. 2010). In most countries, the landscape of gambling has changed dramatically over the last ten to twenty years. The most obvious changes are first that commercial gambling has developed substantially, and second that the emergence of the Internet has provided a fundamentally new platform for gambling with endless potential for gambling opportunities and easy access to gambling. Even though the landscape of gambling has been changing, gambling is based on the same timeless principles; risking money on the outcome of an uncertain future event driven mainly by chance (Dickerson and O'Connor 2006). Adolescent gambling, to a certain degree, both mirrors adult gambling and available gambling opportunities in a society. To a large extent, the type of gambling that young people choose is determined by the type of gambling that is offered and available (Delfabbro and Thrupp 2003; Delfabbro, Lahn et al. 2005)

A major proportion - between 60 to 80 per cent - of adolescents have been engaged in gambling for money during the last year (Derevensky and Gupta 2000; Rossow and Hansen 2003; Jonsson 2006; Welte, Barnes et al. 2009; Frøyland, Hansen et al. 2010), even though most countries have some form of restricted access to gambling activities for underage youths. Among those involved in gambling, a minor proportion experience gambling-related problems (Volberg, Gupta et al. 2010). Despite a lack of consensus about what constitutes problem gambling among adolescents, and uncertainty about what adolescent problem gambling screens measure (Volberg, Gupta et al. 2010), studies that have examined the gambling behaviour of adolescents have typically found the prevalence rates of gambling-related problems up to 2-4 times higher than those of adults (Gupta and Derevensky 1998; Shaffer, Hall et al. 1999; Shaffer and Hall 2001; Derevensky and Gupta 2004). Several studies of adolescent gambling behaviour have shown that the prevalence rates of problem gambling range from 2 to 8 per cent (Olason, Sigurdardottir et al. 2006; Welte, Barnes et al. 2008), where another 10 to 15 
per cent are considered to be 'at-risk gamblers', implying that the people in this group experience some negative consequences from gambling (Jacobs 2000; Hardoon and Derevensky 2002). Adolescents are considered to be an at-risk group for gambling problems and several factors are associated with adolescent gambling behaviour: frequent gambling and problem gambling are more frequent among males (Derevensky and Gupta 2007; Volberg, Gupta et al. 2010) and ethnic minorities (Raylu and Oei 2002; Frøyland, Hansen et al. 2010; Volberg, Gupta et al. 2010). They are also associated with drug and alcohol use, crime, lack of social support, low self-esteem and depression (Volberg, Gupta et al. 2010).

Taking into consideration the fact that gambling is a potentially addictive behaviour, and because gambling problems can disrupt important developmental areas during adolescence, it is important to avoid early exposure of young people to gambling (Stinchfield 2011). In today's society, access to attractive and rewarding activities like gambling is easy and increasing. Structuring the gambling market by regulating access and availability to slot machines is one possible way to restrict gambling behaviour among young people. A close look at how gambling behaviour develops is therefore necessary, in order to understand how a structural intervention may interact with individual behaviour.

\subsection{The aetiology and maintenance of gambling behaviour and problem gambling}

Gambling behaviour can be understood and interpreted from several perspectives and from several levels of explanation. To understand gambling behaviour and problem gambling, one has to account for the whole range of multiplicity in gambling behaviour and problem gambling.

There are a number of pathways to problem gambling and the causal connections are not obvious. Several models have been proposed and the psychological literature is replete with studies exploring risk factors that seem to predispose youth to gambling problems (Nower and Blaszczynski 2004). Albeit, risk factors identified in the individual young person cannot account for an integrated understanding of adolescent gambling behaviour alone and a growing body of literature suggesting different levels of explanation has emerged over the last few years. 
Several researchers have addressed the need for an eclectic approach to gambling behaviour (Griffiths and Delfabbro 2001; Sharpe 2002). This implies models that include various levels of explanation of the development of gambling behaviour. Several models have been proposed. The biopsychosocial model is one such example. This model seeks to include three specific levels of analysis; the psychological, the biological and the social/structural. Isolated, none of these perspectives are sufficient to explain the aetiology of gambling behaviour (Griffiths and Delfabbro 2001). The factors are more likely to interact with one another in the development and maintenance of problem gambling (Sharpe 2002). In other words, a variety of theories in different directions can contribute to a comprehensive understanding of the phenomenon of gambling behaviour. For instance, theories of cognition and superstitious beliefs ${ }^{1}$ (Ladouceur and Dube 1997; Jacobsen, Knudsen et al. 2007), operant and classical conditioning $^{2}$ (Delfabbro and Winefield 1999; Griffiths and Delfabbro 2001; Brunborg, Johnsen et al. 2011), arousal and need/state theories ${ }^{3}$ (Griffiths 1995; Griffiths and Delfabbro 2001; Toneatto and Nguyen 2007), and biological perspectives ${ }^{4}$ (Brewer, Potenza et al. 2007) on gambling behaviour, cover important aspects of the understanding of the phenomenon of gambling and problem gambling behaviour.

The pathways model is another example of an explanatory framework suggested in the understanding of the maintenance and development of gambling behaviour (Blaszczynski and Nower 2002). In the "pathways model of pathological gambling" three sub-groups or "pathways" to describe problem gamblers were identified. According to this model, pathological gambling arises out of a complex interaction of

\footnotetext{
${ }^{1}$ Cognitive theories describe superstitious beliefs and cognitive biases as central in understanding the development and maintenance of gambling behaviour. Cognitive biases are the individual's irrational beliefs, cognitive distortions and erroneous perception about one's ability to influence, control or predict the outcome of an incidental event. Two types of cognitive errors are found to be especially common in gambling behaviour; trying to influence an unpredictable outcome, and an inability to consider random events as independent from each other.

${ }^{2}$ Gambling involves both positive and negative reinforcement and persistent gambling can be viewed as a conditioned behaviour maintained by intermittent schedules of reinforcement. The unpredictability of receiving a random reward may also maintain gambling behaviour, since the gambler anticipates that the next bet will result in a positive outcome.

${ }^{3}$ It has been hypothesized that a primary motivation for gambling behaviour is arousal arising during the gambling session. A relevant example is the experience of "constant near winning" due to the "near miss" effect in slot machines.

${ }^{4}$ Given the same ecological conditions in the form of access to and type of gambling, some gamblers will be more susceptible to developing gambling problems than others. A central issue of this susceptibility is whether or to what extent multiple neurotransmitter systems and genetics are involved in the pathophysiology of pathological gambling.
} 
biological, psychological, social and ecological determinants of problem and pathological gambling. The framework consists of three different pathways to problem gambling;

Figure 2. A pathways model of problem and pathological gambling (Blaszczynski and Nower 2002)

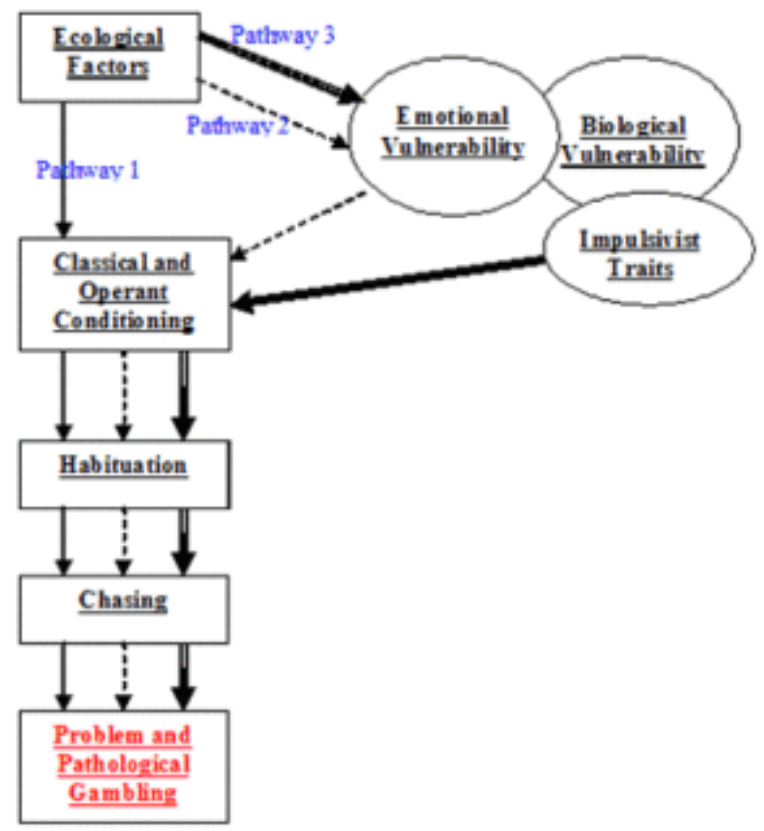

The first pathway describes behaviourally conditioned problem gamblers, who repeatedly exhibit poor judgment by engaging in destructive gambling behaviours, but who do not display any specific psychological pathology. The second pathway describes gamblers who experience gambling problems as a result of depression, anxiety or other emotional disorders. The third pathway describes gamblers identified as antisocial and impulsive problem gamblers, who exhibit signs of antisocial personality disorder, emotional vulnerability, multiple addictions, and other comorbid psychiatric conditions (Blaszczynski and Nower 2002). Common processes in the development of problem and pathological gambling, regardless of pathway, is always initiated through ecological factors (like availability, accessibility and acceptance of gambling), and then depending on the individual's psychological traits (conditioning and cognition). In this 
context, where major interventions have been implemented in the gambling market, ecological factors are central to the understanding of how changes in the availability and accessibility of gambling influence gambling behaviour among adolescents.

In the context of this thesis, two perspectives seem to be especially relevant in the understanding of adolescent gambling behaviour after the regulations in 2006 and 2007. The first is the theory of addiction as excessive appetites (Orford 2001), and the second is the cognitive-affective processing system (CAPS) of Mischel and Ayduk (2004). The theory of addiction as excessive appetites is relevant, because it integrates a whole range of perspectives and features of addiction from the very skewed distribution of consumption, restraint, incentive learning mechanisms with emotional changes as rewards, and emotional regulation cycles, like for instance 'chasing the losses'. Orford (2001) describes these features as primary and secondary processes, which occur within a given socio-cultural context, and which are sufficient to account for the development of a strong attachment for instance to gambling. Among all these perspectives, Orford points out that the very skewed distribution in the consumption of gambling demands precaution in the direction of controlling the gambling market (Orford 2001).

Adolescents are faced with dilemmas, as attractive objects, like slot machines, have been easily accessible in their environment. This represents a challenge for the ability for self-regulation. Humans have a tendency to choose simple short-term gains. According to Mischel and Ayduk (2004), access and availability to tempting and rewarding objects like slot machines creates mental representations of winning at the slot machines. Consequently, the more available gambling is, the more difficult it is to abstain from gambling. More specifically, this can be described as an interaction between the interpretation of a given context and the emotional/affective system. For young people, their level of maturation and stress is crucial for a balanced selfregulation. Mischel and Ayduk (2004) differentiate between two types of cognitive processing influencing the direction of self-regulation: a "cool system" that is slower and more cognitively complex generating more rational, reflective and strategic behaviour, and a "hot system" that enables quick and emotional processing. The hot system is essentially an automatic system, governed by virtually reflective stimulusresponse reactions, consisting of relatively few representations. The balance between the 'hot' and the 'cool' systems depends on two issues: a person's developmental phase 
and the level of stress in the situation. The hot system is well developed at birth, whereas the cool system develops with increasing age (Mischel and Ayduk 2004). As already mentioned, the adolescent brain is neurologically and cognitively immature (Chambers, Taylor et al. 2003), and the ability for self-regulation is less developed. Therefore, environments with easy access to gambling put adolescents at risk for developing gambling problems to a larger extent than adults. Gambling can be associated with stress, both when winning and losing and just by being easily accessible. Metcalfe and Mischel (1999) noted that an increased stress level results in an increasingly dysfunctional "cool system", leaving the "hot system" to dominate processing. Consequently, adolescents must both relate to the presence of attractive temptations, as gambling represents, while at the same time they must cope with developmental tasks due to young age and immaturity. Such increased levels of stress and a dominating hot system, make the regulation of self more difficult. If attractive stimuli (like slot machines) are less available or less attractive, the balance between the hot/cool systems will be transformed over to cool mental representations, making selfregulation easier. Immaturity and exposure to stressful environments transform the balance towards the hot system, making self-regulation challenging. This implies that for young people, structuring the environment towards lesser access and availability to gambling might contribute to reducing stress and balancing the ability for selfregulation.

\subsection{Gambling behaviour - from individual to aggregated levels of understanding}

Gambling and problem gambling behaviour have been an issue for increased interest among clinicians, researchers and regulators, but the public debate regarding gambling and health has mainly focused on the individual health level rather than on a broader population-based level (Korn and Shaffer 1999).

The assessment of clinical subgroups in order to understand the development and maintenance of problem gambling better has some very important clinical implications regarding treatment. This is also of crucial importance for the individual and his or her family. However, from a preventive and public health point of view, efforts targeted at the individual are of limited value for society as a whole. Consequently, the ecological factors described in the pathway model are in the first line for preventing gambling- 
related problems on a population level. Rose (1992) claims that there is a need to raise the understanding that the small group of problem gamblers represents the tail of the population distribution, as they belong to the rest of the population and must be understood in a population context.

The importance of ecological factors is well documented. A study by Grun and McKeigue showed that an increase in overall gambling expenditure in the UK population (in response to the introduction of a new lottery) led to an increase in the proportion of excessive gamblers (Grun and McKeigue 2000). Similarly, Room found more gambling and gambling problems among local residents after the opening of a casino in Niagara Falls in 1996 (Room, Turner et al. 1999). It is a widely-accepted public health view that the more a product is supplied in an accessible form, the greater the volume of consumption and the greater the incidence and prevalence of harm (Orford 2005). The importance of the availability of gambling has also been thoroughly documented by official review bodies in Australia (Australia Productivity Commission 1999), the USA (National Research Council 1999) and the UK (Gambling Review Body 2001).

A public health perspective on gambling aims to move beyond gambling as an individual behaviour (Korn, Gibbins et al. 2003) targeting the population as a whole. Rose (1985) argues that to find the determinants of prevalence and incidence rates in a population, we need to study characteristics of populations, not characteristics of individuals. Furthermore, he claims that new incidents will occur if the underlying causes of the problem stay unresolved (Rose, 1992). Translating this to the gambling field, the question is how we can best be able to prevent gambling-related harm for most people over time.

Studies of social groups and populations provide a relevant focus to understand a phenomenon, like gambling behaviour, from a public health perspective. As West (2007) states: The rules governing group and population behavior may not be the same as those governing the behavior of individuals. There should, however be linkage between the two (West 2007). Rose (1992) argues that health statistics and epidemiological research have focused on counting the number of "cases", defining sickness and deviance away from normality, rather than seeing the prevalence of 
"sickness" as a function of its total mass - or the population average (Rose 1992 p72). The question is then - what is to be prevented?

There are no easy solutions to how gambling problems among adolescents can be or should be prevented. This is a controversial issue, both nationally and internationally, where some people advocate collective restrictions on access to gambling (Adams, Raeburn et al. 2009), while others argue more for harm minimization and responsible gambling efforts (Blaszczynski, Ladouceur et al. 2004). Revenue from gambling is both an important source of income for welfare and humanitarian purposes, and good business for a constantly increasing commercial gambling industry. In other words, this is a field with conflicting interests. In this context, youth gambling represents a potentially serious public policy and health issue (Derevensky, Shek et al. 2010).

The traditional frames of gambling fail to consider research on the social and economic impacts of gambling. Rather, gambling is viewed as a matter of individual freedom and as a form of recreation (Korn, Gibbins et al. 2003). In other areas, like tobacco and alcohol research, the public health perspective is well established (WHO 2009; Babor 2010). Policies oriented towards protecting and preventing youth gambling problems need to be incorporated into organized, national policies to address problem gambling. Such prevention initiatives are largely lacking and only beginning to be made in several countries.

As we have seen, gambling behaviour and problem gambling are governed by a complex set of interrelating factors (Griffiths and Delfabbro 2001; Orford 2001; Messerlian, Derevensky et al. 2004; Mischel and Ayduk 2004). A public health perspective of gambling is proposed as being an appropriate framework for the prevention of gambling-related problems (Korn and Shaffer 1999). Until recently, the individual level perspective has received most attention in the gambling field, and intrapersonal and interpersonal level factors have been in focus both for research, prevention programmes and treatment facilities (Messerlian, Derevensky et al. 2005; Adams, Raeburn et al. 2009). In this thesis, I aim to go beyond the individual level and approach gambling and problem gambling among adolescents from a public health perspective. 


\subsubsection{Levels of prevention}

A relevant question regarding problem and pathological gambling is how much effort should be targeted directly to the harm caused by gambling, and how much should be addressed to what determines the harm. Messerlian and colleagues (2005) emphasize the importance of addressing youth gambling behaviour along a continuum, and that there is a need for different forms of intervention to address the various levels of risk.

Traditionally, prevention initiatives have been categorized into three levels (DicksonGillespie, Rugle et al. 2008); Primary prevention: measures to prevent individuals in the general population from becoming problem gamblers, secondary prevention: measures to prevent the development of problem gambling in individuals with risk factors for the condition, and tertiary prevention: measures to stop and potentially reverse the problems occurring in existing problem gamblers, e.g. with treatment (Williams, West et al. 2007). In this thesis, I examine gambling behaviour among Norwegian adolescents at the group and population levels by looking at how policy measures directed at the gambling market influence gambling behaviour among adolescents. This implies that we target more on the determinants of the harm than the harm caused by gambling. Gambling regulation and changes to the structural level might serve as interventions for both public health and individual health. Subsequently, this thesis belongs to the primary prevention level in this three level categorization, in the sense that we have been looking at policy measures targeted at the population as a whole.

\subsubsection{Adolescent gambling from a public health perspective}

There is a considerable literature on adolescent alcohol, smoking and substance use, and prevention efforts (Romer 2003; Lesch, Walter et al. 2011). The public health approaches are well acknowledged in these fields of prevention. But according to Derevensky and colleagues (2001 cited in Messerlian et al. 2004), there is little empirical knowledge about the prevention of youth gambling problems, and few scientifically-based initiatives. However, several researchers in the gambling field have advocated that gambling issues should be examined from a public health perspective (Shaffer and Korn 2002; Korn, Gibbins et al. 2003; Messerlian, Derevensky et al. 2005), and that the field of youth gambling can make use of the already existing public health approaches available for the prevention of alcohol and drug use in adolescence (Messerlian, Derevensky et al. 2004). According to Shinogle and co-workers (2011), 
epidemiological research has played a vital role in identifying factors that influence the development of disease and other health-related events. They further claim that this is a critical tool in public health and also central in the design of effective prevention programmes and in the planning of treatment services.

Korn and Shaffer (1999) were among the first to encourage the application of a public health approach to gambling. The public health approach is a population level approach that encourages a multidimensional approach to the understanding of public health issues (Korn and Shaffer 1999; Shaffer and Korn 2002; Korn, Gibbins et al. 2003). A public health approach to understanding a disease or disorder in the population depends, to a great extent, on epidemiology to provide an understanding of how the disease or disorder is distributed in the population.

Figure 3. Gambling and the Health of the Public (Shaffer and Korn 2002; Korn, Gibbins et al. 2003)

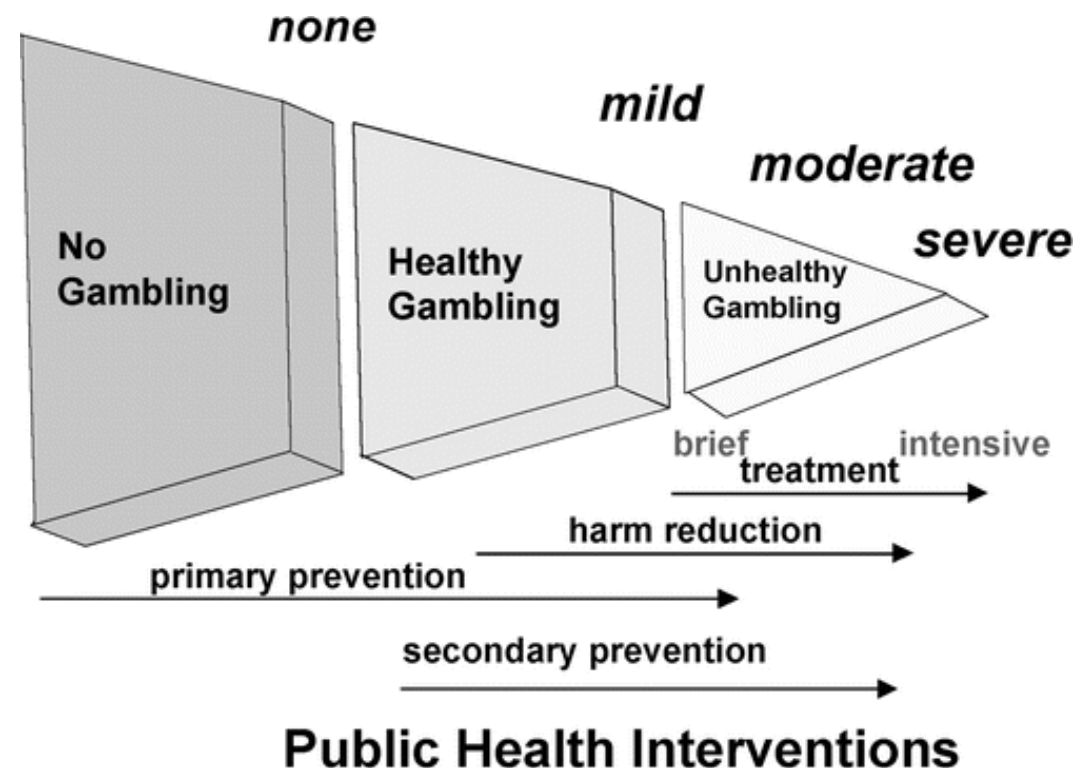

Korn and colleagues (2003) illustrate a framework for gambling and public health in the figure above by emphasizing that gambling behaviour and prevention exist along a 
spectrum, rather than being a dichotomized phenomenon consisting of normal gamblers and pathological gamblers. Secondary and tertiary prevention efforts are important parts of a public health perspective on gambling. However, in the following I will emphasize prevention at a population level, and explain how a population strategy of prevention has important health implications for the population as a whole.

Efforts directed at individuals - also called the high risk strategy - are of great value if they reach the minority of people with special problems rather than the majority of people who are regarded as normal. But this strategy will not limit the incidence of the problem. A problem group (in this case problem gamblers) does not exist in a vacuum in the population. It is linked to the state of the population in general (Rose 1992). This phenomenon has been expressed as the prevention paradox: "a measure that brings large benefits to the community offers little to each participating individual" (Rose 1981) (p. 1850). In other words, in the conceptualization of prevention strategies, we must aim to clarify the various levels of prevention and also acknowledge the population strategy in the prevention of gambling problems among youths.

\subsubsection{The total consumption model}

In a public health approach to gambling, the distribution of consumption of gambling in a population is of relevance. Therefore, in this context, the total consumption model is highly relevant (Govoni 2000; Grun and McKeigue 2000; Chipman, Govoni et al. 2006). Both clinicians and researchers have emphasized the similarities between gambling and other addictions such as alcohol dependence. And diagnostically, we have seen a transition from problem gambling basically being considered to be an impulse control disorder, to problem gambling now being seen more as an addiction. Govoni (2000) has suggested that epidemiological models that have succeeded in describing population level drinking behaviours are also applicable to gambling. This model is usually referred to as 'the total consumption model' or 'the single distribution theory', and it has its origin from alcohol epidemiology. The central point in this model is the existence of a close association between total consumption and the prevalence of heavy drinkers in a population (Ledermann 1956, as cited in Skog 1985).

Empirical analyses from various populations have demonstrated that the higher the total alcohol consumption - or the mean consumption - in a population, the higher is the 
prevalence of heavy drinkers in that population, and vice versa (Lemmens 1991(Skog 1985; Skog 1991a; Skog 1991b; Skog and Rossow 2006). The total consumption model posits that the consumption of alcohol in a population is very skewed, which implies that a very small fraction of the population stands for the most part of alcohol consumption. The distribution of alcohol consumption is described by a highly skewed lognormal curve with a long right tail. The skewness is not altered by changes in consumption, and the number of so-called heavy drinkers in a population increases with increasing mean level of alcohol consumption (Skog 1985; Skog 1991a; Skog 1991b; Skog and Rossow 2006).

As already discussed on page 19, a few studies from various countries have examined the applicability of the total consumption model to gambling (Room, Turner et al. 1999; Grun and McKeigue 2000). In addition, a study by Chipman and colleagues (2006) described the skewed distribution of gambling in a single population, and how the risk of experiencing symptoms of gambling-related problems increased non-linearly with increased gambling consumption (Chipman, Govoni et al. 2006). Finally, a Norwegian study demonstrated a close association between population mean and prevalence of problem gambling in various populations (Lund 2008). All these studies suggest that the higher the level of total (or average) gambling in a population, the higher is the prevalence of problem gamblers, and vice versa. Some empirical evidence thus indicates that the total consumption model also seems to apply to gambling and problem gambling, at least among adults. So far, similar studies have not been carried out on youth populations. Nevertheless, it is assumed that the same 'rules of distribution' are also valid for adolescent gambling behaviour.

In other health areas like weight and blood pressure, Rose and Day (1990) have argued for the validity of the total consumption model, as they found a close association between the population mean and the prevalence of sickness. They noted that "the population mean predicts the number of deviant individuals" and thus that "... the problem of the high risk deviant minority can be understood only when considered in the context of the whole population" (Rose and Day 1990). More recent studies have also shown that depressive symptoms (Veerman, Dowrick et al. 2009) and prescription psychotropic drug use (Bramness and Rossow 2010) display the same distribution as suggested by the total consumption model. 
Although a few studies have suggested that the total consumption model applies to gambling, we do not know in what way it does so. Skog (1985) concluded that there is a strong collective component in alcohol consumption, and that 'the population tends to move in concert up and down the scale of consumption'. This theory is based on the theory of social learning; how through interaction we influence each other in a social system (Bandura 1986). Whether gambling behaviour follows the same collective pattern is not known. We know however, that gambling behaviour among adolescents is influenced by the gambling behaviour of parents and peers (Frøyland, Hansen et al. 2010; McComb and Sabiston 2010), and thus, is affected by social learning and influences from their social system.

The implications of the total consumption model for prevention are significant, as the model predicts that a reduction in the population mean will also imply a reduction in the prevalence of the problem in question (Rose and Day 1990). In the wake of Rose's (1992) theory of prevention and the total consumption model, Messerlian (2004) claims that we must consider both the effect of an increase and decrease of the exposure to gambling on youth gambling behaviour. In that respect, the total consumption model can improve our understanding of the underlying dynamics of adolescent gambling behaviour in the population.

In Norway, gambling has become more easily available and more acceptable over a relatively short period of time, and adolescents spend more time and money on gambling today than they did ten to twenty years ago. When the structural interventions were implemented in the Norwegian slot machine market in 2006 and 2007, similar interventions had never been used in any other country. Knowledge about whether or to what extent structural changes in the gambling market influence gambling behaviour is lacking, and it was necessary to take a closer look at the connection between these structural interventions and gambling and problem gambling behaviour among adolescents. 


\section{Specific aims of the study}

As mentioned in the introduction, the main aim of this thesis is whether and to what extent the level of gambling involvement in a population influences gambling behaviour among Norwegian adolescents. And further, whether and to what extent structural changes in a gambling market, as we have seen in Norway in 2006 and 2007, influence gambling and gambling behaviour in the youth population.

We wanted to assess whether the total consumption model applied to gambling and problem gambling among youth at a general level. In addition we wanted to give a more nuanced picture of various levels of gambling frequency after the Norwegian slot machine regulation, by examining whether the decreases in gambling frequency were observed only at high to excessive levels of gambling or also at moderate gambling levels.

The applicability of the total consumption model was addressed in a two-stage manner, applying both individual level data and aggregate level data:

- At the individual level we wanted to assess to what extent indicators of problem gambling are associated with frequency of gambling in general and frequency of slot machine gambling in particular, and with gambling expenditure.

- At the aggregate level we wanted to assess whether or to what extent average gambling frequency and average gambling expenditure are associated with the prevalence of very frequent gamblers and the prevalence of problem gambling.

By investigating the above-mentioned questions, we aimed to gain important knowledge about whether problem gambling and level of gambling involvement are associated at both individual and aggregate levels. It was reasonable to expect a decrease in average gambling frequency after prohibition of the banknote acceptors in 2006. If we consider slot machine gambling as a particularly addictive game, is it then possible that the decrease in overall gambling frequency was due to reduced gambling among problem gamblers and did not affect all the other gamblers? 
- Based on this, we wanted to assess whether there is a systematic displacement at all levels of gambling behaviour with different mean values of gambling behaviour among adolescents, across different population samples and over time within the same population.

The total removal of all banknote acceptors on all slot machines at the same time was a unique opportunity to assess whether this regulation of the Norwegian slot machine market had any impact on youth gambling behaviour. Previously, in other countries, structural changes implemented on slot machines have been limited to very small changes (like reduction in the size of banknote denomination in Australia), and knowledge about specific structural changes has been lacking. Therefore we wanted to assess:

- whether gambling frequency, gambling expenditure and problem gambling among young people decreased in response to the prohibition of banknote acceptors on slot machines in 2006.

Further, we wanted to assess whether and to what extent changes in gambling behaviour have taken place among Norwegian adolescents after the introduction of the two interventions of the gambling market. However, because a national policy intervention, as we have seen in the Norwegian gambling market, is challenging to evaluate in a conventional design with pre and post intervention observations and an experimental and control group setting, it is important to address whether, or to what extent, observations from intervention designs may be interpreted with respect to intervention effect. The implications of these market changes may represent significant threats to interpretation of intervention effects from a simple pre and post intervention design. More specifically we have addressed:

- Whether the two regulatory interventions in the Norwegian slot machine market were associated with a decrease in gambling problems among Norwegian adolescents 
- Whether changes in internet gambling confounded these associations

- Whether there were indicators of changes in the content validity of the problem gambling measure during this period of multiple significant changes in the gaming and gambling market for young people. 


\section{Material and methods}

\subsection{Design}

This thesis is built upon four papers. Originally, the studies for this thesis were planned to have a longitudinal design, and the data collection was organized as panel data.

Unfortunately, during the process of file merging, we discovered significant numbers of gender change among the pupils, indicating that some errors had occurred in the collection of data at T2 and T3. After merging the files, we were left with only $1 / 3$ of the initial sample, and even though we had removed classes with more than 10 per cent gender change, we still could not trust that we had a correct file of longitudinal data. Consequently, the longitudinal data file was rejected and the studies for this thesis are based on cross-sectional data where groups are compared year by year.

Still, the design of this research is rather unique, due to two aspects. First, it is extremely rare that major interventions such as we have witnessed in the Norwegian gambling market are implemented so systematically and so well organized as we have seen here, with the prohibition of banknote acceptors on all slot machines in July 2006, and the prohibition and removal of all slot machines from one day to the next in July 2007.

Figure 4 shows the timing of our data collections in relation to the interventions in 2005 and 2006.

\begin{tabular}{|l|l|l|l|l|l|}
\hline T1 & T2 & & T3 & & T4 \\
\hline $\begin{array}{l}\text { September } \\
2004\end{array}$ & $\begin{array}{l}\text { September } \\
2005\end{array}$ & July 2006 & $\begin{array}{l}\text { September } \\
2006\end{array}$ & July 2007 & $\begin{array}{l}\text { April } \\
2008\end{array}$ \\
\hline $\begin{array}{l}\text { No changes in the } \\
\text { gambling market }\end{array}$ & $\begin{array}{l}\text { Prohibition } \\
\text { of banknote } \\
\text { acceptors }\end{array}$ & $\begin{array}{l}\text { No } \\
\text { banknote } \\
\text { acceptors }\end{array}$ & $\begin{array}{l}\text { Prohibition } \\
\text { of all slot } \\
\text { machines }\end{array}$ & $\begin{array}{l}\text { No slot } \\
\text { machines }\end{array}$ \\
\hline
\end{tabular}

Second, the time points for our data collections fit very nicely with these interventions, as we have two data collections before any intervention in 2004 and 2005, one data collection after the banknote prohibition (in 2006) and one data collection after the prohibition and removal of all slot machines in 2007 (in 2008). 


\subsection{Material}

The empirical data are comprised of three kinds of data - data from the school survey "Young in Norway - 2002", three Norwegian school surveys ("Regionsprosjektet") in 2004, 2005 and 2006, and finally, a single school survey conducted in 2008.

The study presented in Paper I is based on data from the school survey "Young in Norway-2002", which comprised a national representative net sample of 11637 pupils from lower and upper secondary schools, mainly between 13 and 19 years of age. The survey was conducted in 2002 and covered a wide range of topics. Surveying gambling behaviour included questions about types of games gambled last year, gambling frequency, gambling expenditure, maximum bet and expenditure on slot machines. The Lie/Bet Questionnaire (Johnson, Hamer et al. 1997; Johnson, Hamer et al. 1998) was applied as problem indicator. The criteria of "chasing" from DSM-IV (American Psychiatric Association 2000) were added to ensure a more conservative measure. The pupils were asked to complete the questionnaire at school, participation was voluntarily, and their responses were anonymous. The response rate was 92.3 per cent.

In Papers II and III, the studies were based on three Norwegian school surveys conducted in the same municipalities and schools in 2004, 2005 and 2006. The school surveys were conducted in October/November each year as a joint data collection for two different evaluation projects; partly to assess possible effects of alcohol and drug prevention strategies at the local level, and partly to assess possible effects of national efforts on regulating the slot machine market.

The target population in all three surveys was all students, from lower and upper secondary schools, in grades 8 to 13 in 16 municipalities in Norway. Upper secondary school students were included from both academic and vocational training. In 2004, a written informed parental consent was requested for all students under the age of 18 years. In 2005 and 2006 this was only requested for students in lower secondary schools (grades 8 to 10) whereas a passive informed parental consent from students below 18 years of age in upper secondary schools was obtained. The questionnaire was completed at school during one school hour. Net samples comprised 20703 students in 2004; 21295 in 2005; and 20695 in 2006, and the response rates were $82.7 \%$ (2004), $86.7 \%$ 
(2005) and $85.7 \%$ (2006). The respondents were mainly $13-19$ years old, average age was 15 years and $50 \%$ were girls.

For the fourth study, both the 2005 and 2006 datasets described above for Studies 2 and 3, and a new dataset collected in April 2008, were used. It was not possible, neither economically nor practically, to carry out a data collection of the same size as for the three preceding years. Using the municipalities used for the data collections carried out in 2005 and 2006, schools were selected to give a sample size 1/3 of the original sample size, a geographical diffusion, and the same distribution between lower and upper secondary schools. The questionnaire was completed at school. A written informed parental consent was obtained for students in lower secondary schools and a passive informed parental consent was requested for students below 18 years in upper secondary schools. Net samples comprised 4088 pupils and the response rate was $77.7 \%$. The respondents were mainly 13 to 20 years old, average age was 15.5 years and $50.4 \%$ were girls.

\subsection{Measures}

Demographic variables: Gender and age were applied in all four articles. Degree of urbanization and immigrant background were applied in Article 1. Degree of urbanization was collapsed into three groups; town with more than 15000 inhabitants, smaller town/village, and rural district. Immigrant background was categorized as nonwestern immigrant background when both parents were born in an Asian, African or South-American country, and western background when one or both parents were ethnic Norwegians or from another western country.

Gambling frequency: Gambling frequency behaviour was assessed in terms of frequency of gambling on six various games (slot machines, scratch cards, internet gambling, horse racing, sports betting and lotteries, and 'other forms of gambling') in the preceding 12 months. There were six response categories: 'not gambled last year', 'less than once a month', 'several times a month', 'once a week', 'several times a week' and 'daily or almost daily'. A mid-point value for each category was applied reflecting (approximate) number of times gambled in the past year (i.e. 0, 10, 25, 52, 100 and 220 respectively) for each category of gaming, and the frequency variable were transformed into six semi-continuous variables for number of times gambled during the last year. On 
the basis of these six semi-continuous variables, a sum score for number of times gambled last year for all games was constructed. Internet gambling frequency was assessed somewhat differently for 2006 than for 2005, due to the increased popularity of poker playing among young people at that time. The students in the 2005 survey were asked one question about how often they gambled on the Internet, whereas two questions on internet gambling frequency were asked in 2006 and 2008. In 2005 the question was 'Have you during the last 12 months gambled for money via the Internet?' In 2006 and 2008 two questions were applied to assess internet gambling; 'Have you during the last 12 months played poker for money via the Internet?' and 'Have you during the last 12 months gambled for money on other games via the Internet?' To make these variables more comparable with the 2005 variable, a mean score for number of times gambled on the Internet was constructed (range 0-220 times). A mean score for these two variables in 2006 was applied in order to obtain comparable measures over time.

Gambling expenditure: The students were asked both about maximum expenditure on all forms of gambling ever (6 categories), and total expenditure on slot machines during the last week and last 30 days (open-ended questions).

Problem gambling indicators: Two different instruments were used to assess problem gambling; the Lie/Bet Questionnaire (Johnson, Hamer et al. 1997; Johnson, Hamer et al. 1998) and the South Oaks Gambling Screen Revised for Adolescents (SOGS-RA) (Winters, Stinchfield et al. 1993). The Lie/Bet Questionnaire consists of the following two questions:

- Have you ever felt the need to bet more and more money? (yes/no)

- Have you ever lied to family or friends about how much you gamble? (yes/no)

The Lie/Bet Questionnaire (Johnson, Hamer et al. 1997; Johnson, Hamer et al. 1998) was applied in all four studies. The Lie/Bet Questionnaire has been validated against DSM-IV in three previous studies (Johnson, Hamer et al. 1997; Johnson, Hamer et al. 1998; Götestam, Johansson et al. 2004). The instrument has been found to have very high sensitivity (0.92-0.99) and specificity (0.85-0.96). The study by Götestam and colleagues also included youth samples. In addition, the Lie/Bet questionnaire has been 
shown to have moderate congruence with the SOGS-RA, and to discriminate between youths with high, moderate and low gambling frequency (Rossow and Molde 2006). Further, the Lie/Bet Questionnaire is not a full diagnostic instrument, rather a screening instrument pertaining to the "loss of control" dimensions in the DSM-IV (Rossow and Molde 2006).

Chasing the losses has been shown to be strongly related to loss of control in gambling (O'Connor and Dickerson 2003), and a key criterion in diagnosing pathological gambling (Lesieur and Blume 1987). In Article 1, where the Lie/Bet Questionnaire was the only problem indicator available, a question from SOGS-RA about chasing was added:

- How often do you gamble to win back money you have lost on gambling? (4 categories; 'almost every time I lose', 'most of the times I lose', 'sometimes' and 'never').

In Articles 2 and 4, the Lie/Bet Questionnaire was applied without the question about chasing. The Lie/Bet scores range from 0 to 2, and scores of 1 and 2 are used to categorize at-risk gamblers.

The SOGS-RA (Winters, Stinchfield et al. 1993) was used in Articles 2, 3 and 4. It is one of the most commonly applied instruments in the measurement of problem gambling behaviour among adolescents. It is a 12 item gambling screen adapted from the adult version of SOGS-R (Lesieur and Blume 1987), and is intended for use among adolescents. The SOGS-RA has been found to discriminate well between those who gamble regularly and those who do not (Winters, Stinchfield et al. 1993), and that past year gambling expenditure and gambling frequency are associated with an increasing SOGS-RA (Poulin 2000; Poulin 2002). The SOGS-RA scores range from 0 to 12, and scores of 4 and over are used to categorize problem gamblers. The corresponding scores for at-risk gamblers are 2-3, while no-problem gamblers are in the 0-1 score categories (Winters, Stinchfield et al. 1995).

Several studies have assessed the reliability of this instrument and it has been found to be fairly good to satisfactory, with a value from alpha $=0.74$ to 0.81 (Winters, 
Stinchfield et al. 1993; Derevensky and Gupta 2000; Poulin 2002; Olason, Sigurdardottir et al. 2006; Welte, Barnes et al. 2008). The validity of SOGS-RA has also been shown to be acceptable. Winters and colleagues developed SOGS-RA from SOGS and correlated the revised adolescent version with gambling activity $(r=0.39)$, gambling frequency $(\mathrm{r}=0.54)$ and amount of money spent on gambling last year $(\mathrm{r}=0.42)$. Derevensky and Gupta (2000) also found a fairly high degree of classification agreement (97\%) between the SOGS-RA and DSM-IV-J, which is the rate of true positive. The rate of false negative was $0.5 \%$ and the rate of false positive was $2.4 \%$. In self-report measures, as we have applied in our studies, the content validity is crucial to ensure that the items are representative for and cover the full range of the construct (Field 2009). The SOGS-RA has previously been found to have acceptable validity, but, unfortunately, analysis of content validity has not been carried out during the study period. The possible consequences of this for the interpretation of our findings will be elaborated in the discussion.

Problem gambling is a phenomenon with a relatively low prevalence, and high demands are set for reliability, validity and classification accuracy (Stinchfield 2010). The instruments we apply must reflect important features of gambling behaviour, and this is challenging. According to Stinchfield (2010), the field of youth gambling assessment is in its infancy. An international gold standard in the assessment of gambling problems is lacking, both for adults and adolescents. To minimize measurement errors, the reliability and validity of the measure we use must be acceptable. Reliability refers to the consistency, repeatability and stability of a given measure (Stinchfield 2010), and high reliability is achieved when measurement errors are minimized. We have two types of reliability; temporal stability, which indicates the accordance between the same measure on two different occasions, and internal consistency, which indicates whether the items measure the same construct. Temporal stability is usually measured as testretest stability, and a test-retest stability of $r=0.70$ or higher is satisfactory. An instrument's validity refers to whether the instrument actually measures what it sets out to measure (Field 2009). A central form of validity is construct validity, which is the correlation between an established instrument and a new instrument, aimed at measuring the same construct (Stinchfield 2010). In the discussion, under methodological considerations, I will come back to the challenges of measurement errors. 
Aggregate level: In Article I, the relationship between gambling frequency, expenditure, and the prevalence of frequent gamblers and problem gambling were explored at the aggregate level. Data were transformed from the individual level and aggregated up to school level. The following aggregate measures were assessed:

- measures of overall amount of gambling

$\circ$ average gambling frequency last year

$\circ$ average expenditure on slot machines (last week and last month)

$\circ$ average maximum bet

- measures of very frequent gambling behaviour

$\circ$ proportion of students in the overall 95 percentile on gambling frequency

- gambling expenditure

- measures of prevalence of problem gambling:

○ proportion of students with scores 1 or 2 on Lie/Bet

○ proportion of students meeting both Lie/Bet items, and the "chasing" item from SOGS-RA

○ proportion of students who gambled at least once a week.

As the number of students per school varied, the aggregate data were weighted to account for school size. Very small schools (less than 250 students) were excluded from these analyses.

The use of percentiles: In Article 3, percentiles were used to describe gambling behaviour at various levels within a population. Parallel to Skog's categorization of prototypical drinkers (Skog 1985), we applied four categories of prototypical gamblers based on their levels of gambling frequency:

1) Light to moderate gamblers

(below the $50^{\text {th }}$ percentile; i.e. the $50 \%$ who gambled least frequently)

2) Frequent gamblers

(above the $75^{\text {th }}$ percentile; i.e. the $25 \%$ who gambled most frequently)

3) Very frequent gamblers

(above the $90^{\text {th }}$ percentile; i.e. the $10 \%$ who gambled most frequently)

4) Excessive gamblers

(above the $95^{\text {th }}$ percentile; i.e. the $5 \%$ who gambled most frequently). 
Differences in distributions at the lower levels of gambling frequency could not be obtained, as more than 30 per cent of the adolescents had a score of 10, which was the least possible value on the total gambling frequency variable.

\subsection{Statistical analyses}

Statistical analyses were performed with the Statistical Package for Social Sciences (SPSS) versions 16 and 17.

In Study 1, Pearson's Chi-square statistics were used to test for differences in the distribution of categorical variables and F-test was used for continuous variables. Distributions of variables on gambling frequency and gambling expenditure were described in terms of mean, range and skewness. Associations between means and proportions of gambling behaviour and problem gambling were assessed using correlation coefficients (Pearson's r).

In Study 2, differences between means for the continuous variables were tested using analysis of variance (ANOVA) and F-tests. Differences between proportions were tested using Pearson's Chi-square statistics. Multivariate analyses were conducted to assess the possible impact of the intervention adjusting for trend in gambling behaviour and problem gambling and minor differences in age and gender distribution in the three data collection waves. Logistic regression models were estimated for the binary outcome variables. Multivariate linear regression analysis models were also estimated for the continuous outcome variables. In all models the intervention variable (change from 2005 to 2006) was entered with the possible confounding variables age, gender and trend from 2004 to 2005.

In Study 3, differences in mean values for the total gambling frequency variable between various groups of gamblers and between survey years were tested using analysis of variance (ANOVA) and F-tests. In order to assess whether a difference in mean gambling frequency was associated with a systematic displacement at all levels of gambling, we examined how the four percentiles; the $50^{\text {th }}$, the $75^{\text {th }}$, the $90^{\text {th }}$ and the $95^{\text {th }}$ percentiles were related to the mean. In addition, we also assessed these distribution measures for eight groups of upper secondary school students (divided by survey year, 
gender and study programme at school). Groups with almost the same mean values were treated as one, and this applied to two pairs of groups. Thus, we obtained six subgroups with different mean values on the gambling frequency score. The mean values varied between 24 and 84 . The four percentile values $\left(50^{\text {th }}, 75^{\text {th }}, 90^{\text {th }}\right.$ and $\left.95^{\text {th }}\right)$ were graphically plotted against the mean values for these six sub-groups. Differences in the proportion of gamblers above a certain cut-off value of gambling frequency within each of the four levels of gambling and for each of the two survey years was compared and tested with Pearson's Chi square test.

In Study 4, chi-square statistics and binary logistic regression analyses were applied to assess changes in prevalence of at-risk gambling and problem gambling subsequent to the interventions. Internet gambling frequency was included as co-variate in a second step in these analyses. Possible changes in the content validity of problem gambling was assessed as differences between categories of at-risk/problem gamblers over time with respect to gambling behaviour and other indicators of problem gambling. Possible differences between these groups were further explored in discriminant analyses, a technique for multivariate assessment of group differences. F-tests were used for differences between at-risk and problem gamblers in 2006 versus 2008. 


\section{Results}

Several questions have been addressed in this thesis. In this section, I will summarize the findings in the order in which the study aims were presented previously. Among other things, we addressed whether the total consumption model applies to gambling and problem gambling among youth. This was addressed in a two-stage manner, applying both individual level data and aggregate level data.

At the individual level we assessed whether or to what extent indicators of problem gambling were associated with frequency of gambling in general and frequency of slot machine gambling in particular, and with gambling expenditure.

We found that the majority of respondents $(78.5 \%)$ had gambled during the last year and $57 \%$ of them had done so at slot machines. The overall gambling frequency and slot machine expenditure was skewed to the right, as the majority had no spending on gambling, or gambled less frequently than the average of 48 times per year. The $6.1 \%$ who scored positively on both Lie/Bet items (indication of problem gambling), accounted for $59 \%$ of all gambling expenditure on slot machines. Both gambling frequency and expenditure on slot machines was much higher among those who displayed symptoms of gambling problems, and gambling frequency and expenditure increased with increasing symptoms.

At the aggregate level we wanted to assess whether or to what extent average gambling frequency and average gambling expenditure are associated with the prevalence of very frequent gamblers and the prevalence of problem gambling.

We found that the higher the total amount of gambling or the higher the total amount of slot machine expenditure, the higher was the proportion of very frequent gamblers and the proportion with very high expenditure. Further, positive and significant correlations between various indicators of problem gambling and the overall amount of gambling at the aggregate (school) level imply that the higher the overall amount of gambling and gambling expenditure are, the higher the prevalence of problem gambling. This indicates that the total consumption model also applies to gambling behaviour among adolescents. 
So far we have demonstrated that how often adolescents gamble, and how much money they spent on gambling, are related to problem gambling, both at the individual and aggregate levels, and thus that the total consumption model applies to gambling behaviour. We also wanted to assess whether the decrease in overall gambling frequency was due to reduced gambling among all gamblers, or whether it was only reduced by problem gamblers.

Based on this, we assessed whether there was a systematic displacement at all levels of gambling behaviour with different mean values of gambling behaviour among adolescents, across different population samples and over time within the same population.

In other words, we wanted to find out whether a change in mean population gambling frequency was accompanied by a systematic displacement at all levels of gambling frequency among adolescents, across different population samples and over time in the same population. A very skewed distribution of gambling frequency was evident; the mean was 2.4 times higher than the median and $11.3 \%$ of the gamblers had a gambling frequency score above two times the average. A strong regularity in the distribution of gambling behaviour was observed and gambling at all levels, from light and moderate to frequent and excessive gambling, varied systematically with mean gambling frequency. Thus, a change in the population mean was accompanied by a systematic displacement at all levels of gambling behaviour and not only at high to excessive levels of gambling. In other words, a collective downward shift in gambling frequency was observed.

In 2006 banknote acceptors were prohibited on all slot machines from one day to the next and turnover was reduced by 40 per cent. We addressed the impact of prohibition of banknote acceptors on gambling behaviour and gambling problems among Norwegian adolescents by assessing whether gambling frequency, gambling expenditure and problem gambling among young people decreased in response to the prohibition of banknote acceptors on slot machines in 2006. 
No significant changes in gambling behaviour and problem gambling were observed in the period prior to the intervention; during this two-year period (2004 to 2005), the level of gambling behaviour was more or less stable. After the intervention in 2006, slot machine gambling frequency was reduced by 20 per cent, the proportion that gambled frequently on slot machines was reduced by 26 per cent, and the overall gambling frequency (all games) was reduced by 10 per cent. All indicators of problem gambling showed a significant decrease from 2005 to 2006; i.e. from before to after removal of banknote acceptors, also after controlling for potential confounders such as age, gender and a possible trend from 2004-2005.

It is generally known that boys gamble more often, spend more money on gambling and more often report gambling-related problems, compared to girls (Derevensky \& Gupta, 2004; Hansen \& Rossow, 2008), but we did not find any significant gender (or age) differences in the reduction of gambling behaviour and prevalence of problem gambling from 2005 to 2006, before and after the removal of banknote acceptors.

As previously mentioned, one year after the banknote acceptor ban, all slot machines were prohibited and removed from the Norwegian gambling market and slot machine gambling was no longer possible. We wanted to address whether, or to what extent, observations from simple pre and post intervention designs can be interpreted with respect to intervention effects. The questions we asked were first, whether the two regulatory interventions in the Norwegian slot machine market were associated with a decrease in gambling problems among Norwegian adolescent, second, whether changes in internet gambling confounded these associations, and third, whether there were indicators of changes in the content validity of the problem gambling measure during this period of multiple significant changes in the gaming and gambling market for young people.

When the prevalence of at-risk, problem and pathological gambling decreased after the removal of banknote acceptors in 2006, it increased again after the complete removal of slot machines in 2007. Controlling for age and immigrant background did not alter this finding and additional control for internet gambling frequency moderated these differences only modestly. In other words, the decrease in gambling-related problems 
measured with SOGS-RA did not continue after the prohibition and removal of all slot machines.

The characteristics of at-risk and problem gamblers varied. In particular this was so between 2008 and the two previous survey years. At the same time, we found that total gambling frequency decreased after the slot machine ban, and gambling on slot machines almost disappeared. As mentioned, internet gambling increased from 2004 to 2008 , but with no particular increase after slot machines were removed. The findings indicate an inconsistent pattern in changes in the prevalence of gambling problems and overall gambling behaviour during and after the interventions.

Despite a decrease in overall gambling frequency, the findings indicate stable to elevated levels of problem gambling among Norwegian adolescents after the slot machine ban in 2007. A shift from slot machines to internet gambling was not observed. Possible explanations for this apparent contradiction may be methodological. 


\section{Discussion}

Norwegian adolescents are involved in gambling for money and the proportion reporting gambling-related problems was shown to be substantial in the time period 2002 to 2008. The main findings of this research can be summarized as follows: First, a close relationship between mean consumption of gambling and proportion of heavy or problem consumers in a population was observed, the distribution of gambling was skewed and a small fraction of the adolescents accounted for the majority of money spent and times gambled. Second, we found that a change in the average level of gambling frequency among adolescents was accompanied by a collective downward shift in gambling frequency at all levels of gambling. In other words, a decrease in mean gambling frequency was associated with a decrease in gambling frequency at all levels of gambling - both among small-scale gamblers, moderate gamblers and among those gambling at frequent to excessive levels. Third, significant decreases in at-risk and problem gambling behaviour, expenditure on gambling and gambling frequency behaviour were observed after the banknote acceptor ban in 2006. Finally, during the whole time period from 2002 to 2008, gambling frequency among youths declined, while problem gambling behaviour showed a more fluctuating trend.

The findings from the four articles in this thesis constitute a significant contribution to the gambling research field. This research is the first to examine how gambling behaviour among adolescents is influenced by structural changes in the gambling market, and how gambling behaviour at all levels of gambling in the youth population varies with the population mean. A collective downward shift in gambling frequency among all adolescents adds new knowledge to the field of youth gambling research, and creates a stronger basis for understanding how gambling behaviour among adolescents is governed by structural frames in society. Further, the repeated measures of gambling behaviour before, during and after the major interventions in the slot machine gambling market add new knowledge in several ways by observations of both decreasing and fluctuating trends in adolescent gambling behaviour in this period. The findings of decreasing gambling frequencies and fluctuating rates of problem gambling during the intervention period are somewhat inconsistent. We suggest that these findings point out some important challenges in the assessment of gambling behaviour in a rapidly 
changing gambling market. The implications of these findings for prevention and further research will be discussed in more detail later in this section.

The majority of Norwegian adolescents between 13 and 19 years of age gamble for money. In 2002, before any gambling market regulations were implemented, almost 80 per cent of Norwegian adolescents between 13 and 19 years of age had been involved in some form of gambling during the last year, and almost 60 per cent had gambled on slot machines. A high degree of gambling involvement was also observed in 2004, 2005, 2006 and 2008, although with a gradually declining trend during this period. After the banknote acceptor ban in 2006, gambling frequency, expenditure and at-risk and problem gambling decreased significantly both among boys and girls. Interventions similar to those implemented in Norway have not been made before, neither in the Nordic countries, nor internationally. However, in some regions in Australia, limiting the banknote denominations allowed on slot machines has been tested out on the adult population. Despite diverse findings, the general trend was that a reduction in banknote denomination influenced expenditure in a downward direction (Commission 1999; Blaszczynski, Sharpe et al. 2001; Brodie, Honeyfield et al. 2003; Sharpe, Walker et al. 2005). The finding of a relatively high level of general gambling involvement is also in line with research on adolescent gambling (Blinn-Pike, Worthy et al. 2010). Declining trends in gambling involvement has been observed among American youths during the period 1992 to 2007 (Stinchfield 2011), despite no changes in the regulations and no interventions being made in the gambling market. The general gambling involvement is still high in Norway, with approximately 65 per cent of the population having gambled during the last year in 2010 (Frøyland, Hansen et al. 2010), but the proportion of the population who have gambled on slot machines is, as expected, almost null.

The very skewed distribution, the positive relationship between mean gambling frequency levels and excessive gambling at aggregated levels, and the finding of systematic displacement of all levels of gambling related to the mean gambling level, are all findings that represent a clear parallel to the alcohol field, and thus provide empirical support for a total consumption model of gambling behaviour among adolescents (Skog 1985; Skog and Rossow 2006). Although the total consumption model has played an important role in the understanding of population dynamics and distribution of alcohol consumption in populations, the model has, with few exceptions 
(Grun and McKeigue 2000; Lund 2008), not been considered much in the field of gambling (Chipman, Govoni et al. 2006), and not at all in youth populations. Skog (1985) emphasized that the collective patterns recognized in the total consumption model, for the most part, are based on cross-sectional data. Longitudinal testing of the total consumption model is needed, and so far, such research is scarce. However, two exceptions exist, albeit investigating various consumers and directions of consumption. The first study examined changes in alcohol consumption in Finland after a liberalization in alcohol policy during the period 1968 to 1969 (Makela 2002). It was found that alcohol use increased in all consumption groups after a 50 per cent increase in per capita consumption. The other study is the one presented in Article 3 in this thesis. We found the same pattern of change (in the opposite direction after the restrictions to the gambling market) at all levels of gambling in various sub-groups of gamblers. A change in the population mean was accompanied by a systematic displacement at all levels of gambling. Of special interest here is it that the same pattern is displayed in two different areas of consumption, with both increasing and decreasing mean levels and with almost forty years' time span between the data collections.

\subsection{The total consumption model and adolescent gambling behaviour}

As already mentioned, and in line with findings from adult gambling populations and alcohol research (Skog 1985; Govoni 2000; Chipman, Govoni et al. 2006; Skog and Rossow 2006), the involvement in gambling was very skewed: Three quarters of the youths gambled less often than the average gambling level, and approximately one tenth of the youths gambled more than twice as often as the average. A very small minority (6 per cent) accounted for almost 60 per cent of the expenditure. This skewed distribution of gambling behaviour implies that a substantial proportion of gambling revenue comes from a small group of problem gamblers, which is paradoxical, because the data in this study is mainly derived from minors. The skewed pattern of gambling behaviour has some important implications for the interpretation of adolescent gambling behaviour. For example, one important finding is the positive relationship between indicators of overall gambling and extent of problem gambling at the aggregate level; the higher the overall amount of gambling or the higher the overall amount of slot machine expenditure, the higher was the proportion of very frequent gamblers and the proportion of adolescents with very high expenditure. We also found that the 
distribution of total gambling frequency (all games) displayed a clear regularity across sub-populations. This means that gambling frequency at all levels of gambling is sensitive to decreases in the mean gambling frequency in the Norwegian population of young people. To explain this in more detail; the percentiles, which are relative markers for different gambling levels, vary systematically with the mean level of gambling frequency, and this variation is also evident across sub-populations. The most interesting finding is not what kind of sub-populations we apply, but rather the fact that in sub-populations with higher mean values, the absolute dispersion is larger; in subpopulations with higher mean frequency levels, the five per cent who gamble most (the $95^{\text {th }}$ percentile), gamble five to six times more frequently than the $95^{\text {th }}$ percentile in the least gambling sub-population with lower average gambling frequency levels.

We compared four levels of gambling frequencies (light to moderate gamblers $\left(50^{\text {th }}\right.$ percentile), frequent gamblers $\left(75^{\text {th }}\right.$ percentile), very frequent gamblers $\left(90^{\text {th }}\right.$ percentile), and excessive gamblers $\left(95^{\text {th }}\right.$ percentile $)$ ) within the adolescent population who had a gambling frequency score above a certain level. They were compared over time (i.e. from 2005 to 2006), before and after the prohibition of banknote acceptors on all slot machines in 2006. We found the same decrease with decreasing mean from 2005 to 2006 at all levels of gambling. Consequently, not only did the excessive and very frequent gamblers decrease their level of gambling, light to moderate gamblers also had a decrease in gambling frequency when the average gambling frequency level decreased. So why is it relevant to consider that gambling at all frequency levels is associated with the mean frequency level? One argument, proposed by Chipman and colleagues (2006), is that the total consumption model is consistent with the multidisciplinary public health approach to gambling. Whether gambling behaviour is influenced by situational factors such as availability of gambling, or whether gambling behaviour adapts and declines after a period of exposure to gambling, has been a much debated issue in the gambling field (see Orford 2005 and commentaries on this). According to the total consumption model, it is not possible to both increase the overall level of gambling in a population (for instance by increasing the market for gambling) and to reduce or stabilize the proportion of excessive gambling. This is relevant in the formulation of gambling policies. From a prevention perspective, it is therefore of great importance to know whether there is a small group of 'excessive gamblers' who 
contribute to the mean, or whether all gambling at all levels 'counts' and thus contributes to the mean.

The findings in this study indicate, as Skog (1985) puts it, that "the population moves in concert upwards along the consumption scale", meaning that gambling at all levels contributes to the mean level in a given population. Subsequently, all gamblers are of as much concern as pathological gamblers. An additional aspect, pointed out by Shinogle and co-workers (2011) is that when the proportion of pathological gamblers consists of a very small minority, at-risk gamblers represent a much larger proportion of the population. Over time, this group can also develop more severe gambling-related problems (Shinogle, Norris et al. 2011). In this context, problem and at-risk gamblers are therefore of further interest because of the likelihood that they represents a relatively larger group (Korn, Gibbins et al. 2003), and their gambling habits can be influenced by changes in norms and attitudes to gambling and implementation of new policy measures. Depending on the measures taken, people at risk for gambling problems can potentially both move towards more severe gambling problems, or towards less risky gambling behaviour (Shinogle, Norris et al. 2011).

Our findings suggest that the total consumption model applies to gambling. This model has its origin in the alcohol field and is mainly supported by research from this field. However, there is controversy about the model, mainly concerning three issues. First, recent research has, surprisingly, shown discrepancies between the consumption indicators of alcohol and the indicators of alcohol-related harm (Rossow 2010). This might imply that the model is not valid in all settings, for all populations and at all times. Second, there has been controversy about the interpretation of Skog's model (Gmel and Rehm 2000; Skog 2000), and third, in the light of this model, controversy regarding possible implications for prevention of alcohol-related harm, has been widely discussed (Rehm 1999; Gmel, Klingemann et al. 2001; Skog 2006).

\subsection{A natural experiment in Norway}

Slot machines have been called 'the crack cocaine of gambling' (Dowling, Smith et al. 2005), and efforts to curb their assumed addictiveness has been discussed (McMillen, Marshall et al. 2004). Considering the Norwegian situation until 2007, with easy access to slot machines and no real age control, it did not come as a surprise that slot machine 
turnover decreased by 40 per cent after the banknote acceptor ban (Lotteritilsynet 2007). What was less obvious was whether and in what direction gambling behaviour among under-age youth would develop after the banknote acceptor ban. We found that gambling frequency, expenditure and problem gambling behaviour decreased significantly after the banknote acceptor ban. The decrease in gambling frequency on slot machines was not followed by any increase in other games. Expenditure on slot machines was significantly reduced and so was the proportion of "big spenders". Natural experiments like this are not common, and banknote acceptors on all slot machines have never been banned in any country before. Thus, this is the first study in which the effect of such an intervention has been evaluated. Previous research has only evaluated some aspects of reducing the cash flow on slot machines, and the general finding was that expenditure on slot machines was reduced (Commission 1999; Blaszczynski, Sharpe et al. 2001; Brodie, Honeyfield et al. 2003; Sharpe, Walker et al. 2005).

We cannot draw causal connections between the banknote acceptor ban and the decline in gambling and problem gambling behaviour after the ban. However, the stability in gambling behaviour prior to the banknote acceptor ban makes this association reasonable. On the other hand, as an objection to this assumption, an American study showed a decline in gambling frequency behaviour among adolescents in the period 1992 to 2007, with no specific interventions in the gambling market (Stinchfield 2011), A recent review of adolescent gambling prevalence studies from North-America, Australia and Europe, indicates the same declining trend (Volberg, Gupta et al. 2010).

How then, can this decrease in general gambling behaviour and at-risk and problem gambling as a response to structural changes to the slot machine market be explained? This may be due to several factors: First, it represents a constraint on gambling. Gambling is more impractical when coins are required to continue gambling. Second, as a consequence of the first, exchanging banknotes into coins gives an opportunity to cool down and rethink whether to continue gambling or not. Third, an intervention like this, which provoked a long-lasting public debate, might also function as a clear signal, maybe with subsequent changes in norms and attitudes to slot machine gambling among youths. Nevertheless, a policy measure on a structural level such as the slot machine ban "talks" to the population in several ways; both directly, as changing banknotes into 
coins is more bothersome, and indirectly, as a consciousness-raising signal that gambling needs to be regulated to prevent gambling-related harm. In addition, for young people still in development regarding their ability to self-regulate, the need to change banknotes into coins to continue gambling might "turn on" the cool mental representations, making self-regulation easier.

\subsection{Contradictory findings - challenges in evaluating policy measures}

The finding that slot machine gambling almost disappeared after the slot machine ban was not very surprisingly. However, the increased prevalence of at-risk and pathological gambling after the slot machine ban was unexpected, especially because it diverges from the development in gambling frequency in the same period. Gambling frequency on all games was significantly reduced in the period 2006 to 2008, and this was despite a significant increase in internet gambling in the same period. Although internet gambling increased significantly during the intervention period, there was no shift from slot machine gambling to gambling via the Internet, and the prevalence rate in 2008 was unchanged, also after controlling for age and the frequency of internet gambling.

A range of epidemiological studies have previously supported a link between the availability of gambling and the prevalence of at-risk, problem and pathological gambling (Room, Turner et al. 1999; Shaffer, Hall et al. 1999; Grun and McKeigue 2000). Considering our findings from Studies 1, 2 and 3, it was reasonable to expect an additional decrease in problem gambling among youths after the slot machine ban. But this was not the case. I will now discuss several possible interpretations of our contradictory findings.

These findings raise the question: How can more youths display gambling-related problems when fewer youths gamble? This study does not answer this question, but there are some possible explanations. It could be that the frequency measures we applied are appropriate for what Olason and colleagues (2010) call "land-based" games, and that gambling via the Internet is not so well captured by counting number of times gambled. There has been a significant development in the gambling market in the period we have monitored, and we have to ensure comparable data year by year, applying the same instruments and frequency questions. Frequency questions might serve as a reasonably good measure for slot machine gambling, but may not capture the 
underlying exposition of internet gambling. Is it possible that internet gambling behaviour is under-reported because the frequency measure is not a sufficient measure, the landscape of gambling has changed tremendously and we still use the same instruments? Internet gambling increased from 2004 to 2008 in our study. Nevertheless, our findings showed that internet gambling frequency moderated the observed changes in prevalence of problem gambling only to a modest extent.

In general, youths are innovative in their interaction with new technology, and it is therefore likely that both gambling behaviour and what gambling constitutes are quite different today than they were 8 to 10 years ago. For instance, a recent study from Iceland has shown that gambling via the Internet has increased more compared to other forms of gambling, and that internet gamblers are more likely to have gambling-related problems compared with non-internet gambling youths (Olason, Kristjansdottir et al. 2011). Further, the Internet serves as a platform for a whole range of activities in adolescents' daily life, with gambling as one of them. The increased prevalence in problem gambling together with the observed decrease in gambling frequency can therefore also be due to the inclusion of adolescents who play online role-playing games (MMPORG), since some of the questions in the SOGS-RA can be misunderstood to include such games. For instance, is it possible that we also have measured something in addition to problem gambling, such as excessive online gaming? In a recent Norwegian study of gambling and online gaming among adolescents, relatively low rates of problem and pathological gambling and online/computer gaming were found (Frøyland, Hansen et al. 2010). The data for these two studies were collected in 2008 and 2010, respectively, and we can ask ourselves: How likely is it that at-risk and problem gambling doubled from 2006 to 2008 (after the slot machine ban), and was then halved from 2008 to 2010 ? We can at least conclude that measuring problem gambling behaviour in a rapidly changing gambling market is challenging. We must have in mind some methodological challenges related to how we measure gambling behaviour among young people in a rapidly changing technology-driven gambling market. Volberg and colleagues call for 'a more nuanced understandings of how these phenomena change in response to changes in the social and cultural environment' (Volberg, Gupta et al. 2010). As an example, in a study from Island, it was found that gambling on typical land-based games (such as slot machines) decreased, while gambling via the Internet increased, and further, internet gamblers were more likely to 
be classified as problem gamblers (Olason, Kristjansdottir et al. 2011). In other words, gambling behaviour and trends among adolescents are changing, also in countries without market interventions. Therefore, we must take into consideration a whole range of factors possibly influencing gambling behaviour and problem gambling among youths.

\subsection{Methodological considerations}

Is SOGS-RA a valid instrument for measuring adolescent gambling? According to Stinchfield (2010), no well-validated instrument exists for diagnosing pathological gambling in adolescents. The most commonly used instruments are the South Oaks Gambling Screen-Revised for Adolescent (SOGS-RA), DSM-IV-Juvenile (DSM-IV-J) and DSM-IV-Multiple Response-Juvenile (DSM-IV-MR-J), the Massachusetts Gambling Screen (MAGS) and a more recently developed instrument, the Canadian Adolescent Gambling Inventory (CAGI). The first three are adaptations of adult versions of gambling instruments and none of them has undergone rigorous psychometric evaluation (Stinchfield 2010). Is it therefore possible that the rates of problem gambling in our studies reflect something else than problem gambling, and that the SOGS-RA instrument has poor specificity due to a changing gambling market? Several challenges in measuring adolescent gambling behaviour have previously been addressed; the cut-off score used to classify adolescent problem gambling is lower compared to adults (Fisher 2000), some of the questions are difficult to understand or irrelevant for adolescents (Ladouceur, Bouchard et al. 2000), and as Ladouceur and colleagues (2005) claim, prevalence rates for adolescent pathological gambling that are based on these instruments are therefore likely to reflect a clinical definition of pathological gambling among adults rather that among youth (Ladouceur, Ferland et al. 2005).

Our findings demonstrated that even among at-risk and pathological gamblers (SOGSRA 2+ and 4+) a significant proportion did not report key characteristics of problem gamblers as generally described in the literature, and we also saw a decreasing trend in the prevalence of some of these characteristics among the at-risk and problem gamblers. Among the at-risk gamblers (SOGS-RA 2+) less than two thirds reported gambling involvement weekly or more often on at least one game, and this proportion was significantly lower in 2008 , compared with previous years. The proportion having 
positive answers on one or both of the Lie/Bet questions was significantly lower in 2008 compared to 2005 and 2006, and even though there has been a significant increase in the proportion of adolescents who report a maximum bet exceeding NOK 100, one third of the at-risk gamblers have never exceeded this level of money spent on one bet. It is also noteworthy that among the pathological gamblers (SOGS-RA 4+), only half reported chasing. In addition, one in five gambled less than weekly, and 25 per cent had never spent more than NOK 100 in one bet. Nevertheless, our findings are based on selfreported data, which is both subjective and retrospective. Of course, it is possible to perceive gambling less than weekly, no chasing losses, and maximum bets below NOK 100 as problematic, but it is also possible that these somewhat contradictory findings are an indication of some methodological challenges.

Finally, our findings have taught us that evaluating gambling behaviour over time in a technologically changing gambling market is challenging. First, the most commonly used instrument to measure adolescent problem gambling behaviour is the SOGS-RA (Stinchfield 2010), revised from the adult South Oaks Gambling Screen (Lesieur and Blume 1987) in 1993 (Winters, Stinchfield et al. 1993). The psychometric properties of this instrument have been addressed and found to have satisfactory internal consistency (Poulin 2002; Welte et al 2008), but the instrument has been criticized concerning the cut-off score (Govoni, Rupcich et al. 1996; Derevensky and Gupta 2000) and whether the questions are understandable for young people (Ladouceur, Bouchard et al. 2000). Second, the SOGS-RA is used in assessing the prevalence of problem gambling and is based on the DSM-III criteria, which are for diagnostic and clinical purposes. Third, and less addressed; the gambling landscape has changed tremendously since these instruments were developed, and they may not capture gambling behaviour as it is today. In the assessment of adolescent problem gambling, new instruments intended for youths must be developed and psychometrically evaluated. In addition, the challenges of a rapidly changing gambling market must be taken into consideration in the measurement of gambling behaviour, because, as Stinchfield puts it: 'Existing instruments are used to make clinical, scientific, and public policy decisions, and therefore, it is critical that these instruments demonstrate evidence of reliability, validity and accuracy' (Stinchfield 2010). 


\subsection{Strengths and limitations of these studies}

Some strengths and limitations of the studies should be mentioned. In retrospect it has been obvious that there are some challenges regarding the measurement of adolescent gambling behaviour and that it could have been useful to apply some more dimensions, in order to increase the accuracy of our observations. Some challenges were noticed on the way. Regarding the shift in gambling preferences among youths in the period 2002 to 2008 , the extent and consumption of gambling may have been under-reported. It is possible that one single measure on frequency counting "number of times gambled..." is not sufficient to survey the extent and consumption of gambling, despite the fact that it is a conventional way of doing so. Future studies should at least include time and money spent on gambling in addition to the frequency measure. Further, we only have cross-sectional data, and can subsequently not assess stability and change in gambling behaviour over time at the individual level. Initially, Study 4 was designed as a mixed panel and cross-sectional study with longitudinal observations of individuals over time (from 2004, 2005 to 2006). As mentioned previously, the panel data was not possible to establish, for practical reasons due to errors during the data collection. Despite fairly high response rates at all points of time, the response rate has been decreasing. We do not know whether this decrease is due to a general trend in decreasing response rates in surveys, or whether it is certain groups of adolescents that fall off.

Another important limitation of our studies is that the instruments we applied have not been validated during the study period. Over time, a construct such as problem and pathological gambling may change and the content validity of the problem indicators we have applied may have changed accordingly. The content validity of an instrument is vulnerable over time. In this context, where we have measured a phenomenon which is so influenced by technological developments, we cannot know for sure that we have measured the same construct. This is because gambling behaviour is changing and the platform for gambling is more and more infiltrated with other tasks such as schoolwork, gaming, contacting friends and so forth. In this landscape of gambling, we have applied the same instruments. Therefore, the content validity of our instruments may be vulnerable to changes over time, to changes in the structure of gambling, and to the fact that young people are quick, and willingly change to new technology. In a way we are left with new questions about measuring gambling behaviour among youths in a rapidly changing technological gambling market. Probably, the factors that condition problem 
gambling change over time, and we must take this into consideration in future studies of adolescent gambling behaviour.

That said, it is also important to highlight the strengths of these studies. In all data collections the net samples were very high with response rates ranging from 83 to 92 per cent. The studies in this thesis were also very well designed, as we had two data collections before any intervention was implemented, serving as a control to the results from post interventions studies. We had one data collection after the first intervention (banknote acceptor ban), and one after the second intervention (slot machine ban).

\subsection{Implications}

The findings of this thesis have several implications, both theoretical, for the prevention of gambling-related problems, and implications for future research.

\subsubsection{Theoretical implications}

One of the most important aspects of our findings is the strong parallel in the distribution of gambling consumption in youth populations and previous research on consumption of alcohol in populations. Gambling at all levels varies systematically with the mean gambling frequency in a given population. The underlying population dynamics of gambling has been found to be very similar to the population dynamics of alcohol use in the population (Govoni 2000). The total consumption model applies to gambling and this implies that much of the alcohol literature may also be applicable to the understanding of gambling behaviour. In addition, epidemiological research can be valuable to help us to understand the underlying dynamics of gambling behaviour. The total consumption model is relevant to a public health perspective on problem gambling, which again is important for prevention; "the close link between mean and prevalence implies that to help the minority, the "normal" majority must change" (Rose and Day 1990). In practice, related to gambling behaviour and gambling problems, the majority of gamblers must reduce their gambling in order to reduce at-risk and problem gambling in the population as a whole.

\subsubsection{Implications for prevention}

Our findings support a population-based approach to the prevention of gambling- 
related problems. In the context of gambling problems, this would imply that in order to reduce excessive gambling in a population, the majority of gamblers must also reduce their gambling. In this respect prevention strategies directed at the total population of gamblers seem highly relevant if they are to be effective in reducing overall consumption of gambling.

The traditional perspective of prevention has been to identify problem gamblers and to offer them support and treatment (Korn et al 2003; Adams et al 2009). But targeting prevention efforts at the small minority of gamblers who gamble most (for instance the $95^{\text {th }}$ percentile), according to our findings, will not influence the incidence of problem gambling. Preventive efforts targeted at the whole population will possibly be a more appropriate strategy, if the goal for prevention is to reduce the number of gamblers in gliding transition between social and problem gambling.

Based on our observations of empirical support for a total consumption model, a population strategy to prevent gambling problems seems to be reasonable. This is a preventive strategy known from a whole range of other areas such as alcohol use, smoking, the use of seat belts in cars and vaccination programmes for children. It seeks to control the determinants of the incidence and not only the prevalence of problems. This is in line with Rose and Day's (1990) notion that strategies directed at the population as a whole are more effective than strategies directed at risk groups. High risk strategies are of course needed and are usually both appropriate and of great value to the individuals they are aimed at. However, preventive efforts should be targeted at different levels. In the context of this thesis, we found a decrease in gambling frequency after the interventions. If we assume that there is a relationship between gambling frequency and the level of problem gambling, this indicates a decrease in gambling-related problems. Based on this, changes at the structural level, as we have seen in the Norwegian gambling market, may serve as a method of protecting vulnerable groups, such as adolescents. This implies that the way our politicians choose to regulate the gambling market might have an impact on public health in our society. A gambling market regulation that aims to curb gambling for everyone will also limit the incidence and prevalence of at-risk gamblers and gambling problems. 
On the other hand, some limitations and problems with a population approach to prevention must be mentioned. A population approach is not a very popular strategy. In several countries where gambling is allowed, gambling revenue is an important source of financing collective welfare, and in many cases a restricted gambling market would require higher taxation levels. Furthermore, some people would argue that a population strategy of prevention affects people who do not have gambling problems, and those who gamble for entertainment and fun. Rehm (1999) describes it using the metaphor: "draining the ocean to prevent shark attacks". Perhaps the most fruitful approach to prevention is to apply a mix of preventive elements (Skog 2006), and, in the context of gambling, have a balance between population and high-risk strategies. So far in the gambling field, much of the focus has been on individual level explanations and solutions (Adams, Raeburn et al. 2009). It remains to be seen whether population and public health strategies in the prevention of gambling-related harm will become more popular among the population in general and policy makers in particular.

\subsubsection{Implications for further research}

As important as the preventive implications accounted for above, are the implications of our finding for future research. The field of gambling research is young compared to the field of alcohol research and it has been pointed out that, despite increasing understanding of youth gambling, we still have a long way to go (Volberg, Gupta et al. 2010). The most central implications from this thesis are the following: First, our findings need to be validated against similar studies based on data sets from other population groups, and other countries and jurisdictions with different types of gambling, different gambling policies and other levels of problem gambling. In Article 3 , we examined various sub-populations in the youth population, and our findings were the same across those. Whether the total consumption model is applicable both to the general adult population and other sub-populations (treatment and prison populations) known to have higher prevalences of gambling-related problems, has so far not been examined. Further, Skog (1985) postulated two assumptions for the observed regularity in the distribution patterns of alcohol; drinking behaviour tends to combine multiplicatively, and an individual's drinking habits are strongly influenced by his or her personal network. Although it is clear that there are many determinants and risk factors for gambling and problem gambling, both at the individual level and at the societal level (Messerlian et al. 2005), it is not clear whether these combine 
multiplicatively. Neither do we know the importance of social interaction and influence on gambling behaviour. Although some studies have shown that the gambling habits of parents and peers increase the risk for gambling problems (Magoon and Ingersoll 2006), a closer examination of whether these assumptions are valid in the field of gambling and problem gambling would be valuable in order to explain the observed strong regularity in the distribution of gambling behaviour.

Except from our findings in Article 3 and the study by Lund (2008), there is little knowledge about the relationship between the mean and the gambling level of various groups of gamblers. Particularly in view of the significant implications for prevention strategies, replications of this study are therefore clearly warranted. This relationship should be examined by applying data from various countries and cultures, and here we have one obstacle; this would require gambling behaviour to be measured in comparable ways across surveys, which has been shown to be difficult enough in our study in Norway. The issue of the validity of prevalence rates of adolescent problem gambling has also been questioned in a number of studies (Ladouceur, Bouchard et al. 2000; Ladouceur, Ferland et al. 2005). Further, more research is certainly needed to improve our understanding of the determinants of the population level of gambling frequency. In line with Rose's arguments (1992), we argue that it is important not only to address individual characteristics and features of the small minority of problem gamblers, but also the characteristics of societies in which the incidence and prevalence of problem gambling are high. 


\section{Conclusions}

This thesis makes an important epidemiological contribution to psychological research on the understanding of the associations between the extent and 'consumption' of gambling and problem gambling behaviour in the youth population.

In summary, the studies in this thesis have demonstrated that problem gambling among youths is associated with level of gambling involvement both at individual and aggregated levels and the distribution of gambling frequency is skewed with a very small proportion of youths accounting for most of the gambling. We found that the total consumption model applies to gambling among youths and that there is a strong regularity in the distribution of gambling behaviour. This means that a decrease in mean gambling frequency was associated with a decrease in gambling frequency at all levels of gambling - both among those who gamble very little, among moderate gamblers and among those who gamble at frequent to excessive levels. Declining trends in the frequency of gambling behaviour were observed in the period 2002 to 2008, and especially after the two interventions in 2006 and 2007. However, the prevalence of atrisk and problem gambling showed a more fluctuating trend.

The findings suggest on the one hand that the prevalence of problem gambling among adolescents is tied to how much all adolescents gamble, and on the other hand, that we have some methodological challenges in the study of a phenomenon with low prevalence, such as problem gambling, both because measures validated for youth do not exists, and because the construct of problem gambling is probably changing due to a rapidly changing gambling market. Further, a dichotomized perspective on sickness and health is well established in our society. The gambling field is no exception. Public apprehension of pathological gambling as a disease that strikes a small minority of deviants is widespread. Our findings support a gliding transition from moderate to excessive gambling, and subsequently also from no-problem gambling to at-risk and pathological gambling. And the most important thing - put simply - if everyone gambles less both the incidence and prevalence of at-risk and problem gambling are influenced in a downward direction. 


\section{$7 \quad$ References}

Adams, P. J., J. Raeburn, et al. (2009). "A question of balance: prioritizing public health responses to harm from gambling." Addiction 104(5): 688-691.

American Psychiatric Association, A. (1980). Diagnostic and Statistical Manual of Mental Disorders. Washington DC: Author.

American Psychiatric Association, A. (2000). Diagnostic and Statistic Manual of Mental Disorders. Washington DC: Author.

Babor, T. F. (2010). "Public health science and the global strategy on alcohol." Bull World Health Organ 88(9): 643.

Bandura, A. (1986). Social foundations of thought and action: A social cognitive theory New Jersey, US, Englewood Cliffs: Prentice-Hall, Inc.

Blaszczynski, A., R. Ladouceur, et al. (2004). "A science-based framework for responsible gambling: the Reno model." L Gambl Stud 20(3): 301-317.

Blaszczynski, A. and L. Nower (2002). "A Pathways model of problem and pathological gambling." Addiction 97: 487-499.

Blaszczynski, A., F. Sharpe, et al. (2001). The assessment of the impact of the configuration on electronic gambling machines as harm minimization strategies for problem gambling. (A report for the Gaming Industry Operatos Group). Sydney, The University of Sydney Gambling Research Unit.

Blinn-Pike, L., S. L. Worthy, et al. (2010). "Adolescent gambling: a review of an emerging field of research." J Adolesc Health 47(3): 223-236.

Bramness, J. and I. Rossow (2010). "Can the total consumption of a medicinal drug be used as an indicator of excessive use? The case of carisoprodol." Drugs: Education, Prevention, and Policy 17(2): 168-180.

Brewer, J. A., M. N. Potenza, et al. (2007). The Neurobiology of Pathological Gambling. Research and Measurement Issues in Gambling Studies. G. Smith, D. C. Hodgins and R. J. Williams. San Diego, Elsevier: 345-370.

Brodie, M., N. Honeyfield, et al. (2003). Change in bank note acceptors on electronic gambling machines in Queensland - Outcome Evaluation., Research and Community Engagement Division; Queensland Office of Gambling Regulation.

Brunborg, G. S., B. H. Johnsen, et al. (2011). "Individual differences in evaluative conditioning and reinforcement sensitivity affect bet-sizes during gambling." Personality and Individual Differences 50(5): 729-734.

Chambers, R. A., J. R. Taylor, et al. (2003). "Developmental neurocircuitry of motivation in adolescence: a critical period of addiction vulnerability." Am J Psychiatry 160(6): 10411052. 
Chipman, M. L., R. Govoni, et al. (2006). The distribution of consumption model: an evaluation of its applicability to gambling behavior Guelph, Ontario, Ontario Problem Gambling Centre.

Commission, A. P. (1999). Australias Gambling Industries. 10.

Delfabbro, P., J. Lahn, et al. (2005). "Further Evidence Concering the prevalence of adolescent gambling in Australia: A study of ACT." International Gabmling Studies 5: 209228.

Delfabbro, P. and L. Thrupp (2003). "The social determinants of youth gambling in South Australian adolescents." L Adolesc 26(3): 313-330.

Delfabbro, P. and A. H. Winefield (1999). "Poker-machine gambling: An analysis of within session characteristics." British Journal of Psychology 90: 425-439.

Derevensky, J. and R. Gupta (2000). "Prevalence estimates of adolescent gambling: a comparison of the SOGS-RA, DSM-IV-J, and the GA 20 questions." J Gambl Stud 16(23): $227-251$

Derevensky, J. and R. Gupta (2004). Gambling Problems in Youth: Developmental and Applied Perspectives. New York, Kluwer Academic/Plenum Publishers.

Derevensky, J. and R. Gupta (2007). Adolescent Gambling: Current Knowledge, Myths, Assessment Stategies, an Public Policy Implications. Research and Measurement Issues in Gambling Studies. G. Smith, D. C. Hodgins and R. J. Williams. San Diego, Academic Press, Elsevier: 438-456.

Derevensky, J., D. T. L. Shek, et al. (2010). "Adolescent Gambling." International Journal of Adolescent Medicine and Health 22(1): 1-2.

Dickerson, M. and J. O'Connor (2006). Gambling as an Addictive Behaviour - Impaired Control, Harm Minimisation, Treatment and Prevention. Cambridge, Cambridge University Press.

Dickson-Gillespie, L., L. Rugle, et al. (2008). "Preventing the Incidence and Harm of Gambling Problems." Journal of Primary Prevention 29: 37-55.

Dowling, N., D. Smith, et al. (2005). "Electronic gaming machines: are they the 'crackcocaine' of gambling?" Addiction 100(1): 33-45.

Fekjær, H. O. (2001). Spillegalskap - vår nye landeplage. Oslo, Gyldendal Akademisk.

Field, A. (2009). Discovering statistics using SPSS. London, Sage.

Fisher, S. (2000). "Developing the DSM-IV-DSM-IV criteria to identify adolescent problem gambling in non-clinical populations." L Gambl Stud 16(2-3): 253-273.

Frøyland, L. R., M. Hansen, et al. (2010). Uskyldig moro? Pengespill og dataspill blant norske ungdommer. Oslo, NOVA - Norsk Institutt for forskning om oppvekst, velferd og aldring. 
Gmel, G., S. Klingemann, et al. (2001). "Revising the preventive paradox: the Swiss case." Addiction 96(2): 273-284.

Gmel, G. and J. Rehm (2000). "The empirical testability of Skog's theory of collective drinking behaviour." Drug and Alcohol Review 19: 391-399.

Govoni, R. (2000). Gambling Behavior and the Distribution of Alcohol Consumption Model. Department of Psychology. Windsor, University of Windsor. Degree of Doctor of Philosophy.

Govoni, R., N. Rupcich, et al. (1996). "Gambling behavior of adolescent gamblers." Journal of Gambling Studies 12(3): 305-317.

Griffiths, M. (1993). "Fruit machine gambling: The importance of structural characteristics." Journal of Gambling Studies 9(2): 101-120.

Griffiths, M. (1995). Adolescent Gambling. London, Routledge.

Griffiths, M. and P. Delfabbro (2001). "The Biopsychosocial Approach to Gambling: Contextual Factors in Research and Clinical Interventions." Journal of Gambling Issues.

Grun, L. and P. McKeigue (2000). "Prevalence of excessive gambling before and after introduction of a national lottery in the United Kingdom: another example of the single distribution theory." Addiction 95(6): 959-966.

Gupta, R. and J. Derevensky (1998). "An Empirical Examinination of Jacobs' General Theory of Addictions: Do Adolescent Gamblers Fit the Theory?" Journal of Gambling Studies 14(1): 17-49.

Gupta, R. and J. Derevensky (2000). "Adolescents with gambling problems: from research to treatment." L Gambl Stud 16(2-3): 315-342.

Götestam, K. G., A. Johansson, et al. (2004). "Validation of the Lie/Bet screen for pathological gambling on two normal population data sets." Psychological Reports 95(3): 1009-1013.

Hansen, M. and R. Skjerve (2006). Game Over - Selvhjelpsbok for spilleavhengige. Oslo, Gyldendal Akademisk.

Hardoon, K. K. and J. Derevensky (2002). "Child and adolescent gambling behaviour: Current knowledge." Clinical Child Psychology and Psychiatry 7(2): 263-281.

Jacobs, D. F. (2000). "Juvenile gambling in North America: an analysis of long term trends and future prospects." J Gambl Stud 16(2-3): 119-152.

Jacobsen, L. H., A. K. Knudsen, et al. (2007). "An overview of cognitive mechanisms in pathological gambling." Nordic Psychology 59(4): 347-361.

Johnson, E. E., R. Hamer, et al. (1998). "The Lie/Bet Questionnaire for screening pathological gamblers: a follow-up study." Psychol Rep 83(3 Pt 2): 1219-1224. 
Johnson, E. E., R. Hamer, et al. (1997). "The Lie/Bet Questionnaire for screening pathological gamblers." Psychol Rep 80(1): 83-88.

Jonsson, J. (2006). "An overview of prevalence surveys of problem and pathological gambling in the Nordic countries." Journal of Gambling Issues(18).

Korn, D. A., R. Gibbins, et al. (2003). "Framing public policy towards a public health paradigm for gambling." Journal of Gambling Studies 19(2): 235-256.

Korn, D. A. and H. J. Shaffer (1999). "Gambling an the Health of the Public: Adopting a Public Health Perspective." Journal of Gambling Studies 15(4): 289-365.

Ladouceur, R., C. Bouchard, et al. (2000). "Is the SOGS an Accurate Measure of Pathological Gambling Among Children, Adolescents and Adults?" Journal of Gambling Studies 16(1): 1-24.

Ladouceur, R. and D. Dube (1997). "Erroneous perceptions in generating random sequences: Identification and strength of a basic misconception in gambling behavior." Swiss Journal of Psychology 56(4): 256-259.

Ladouceur, R., F. Ferland, et al. (2005). "Concordance between the SOGS-RA and the DSM-IV criteria for pathological gambling among youth." Psychology of Addictive Behaviors 19(3): 271-276.

Lesch, O., H. Walter, et al. (2011). Prevention strategies, Springer Vienna.

Lesieur, H. R. and S. B. Blume (1987). "The South Oaks Gambling Screen (SOGS): a new instrument for the identification of pathological gamblers." Am J Psychiatry 144(9): 11841188 .

Lotteritilsynet (2007). Statistics 2007. Førde, Norway, The Norwegian Gaming Authority.

Lund, I. (2008). "The population mean and the proportion of frequent gamblers: is the theory of total consumption valid for gambling?" L Gambl Stud 24(2): 247-256.

Magoon, M. E. and G. M. Ingersoll (2006). "Parental modeling, attachment, and supervision as moderators of adolescent gambling." L Gambl Stud 22(1): 1-22.

Makela, P. (2002). "Whose drinking does the liberalization of alcohol policy increase? Change in alcohol consumption by the initial level in the Finnish panel survey in 1968 and 1969." Addiction 97(6): 701-706.

McComb, J. and C. Sabiston (2010). "Family Influences on Adolescent Gambling Behavior: A Review of the Literature." Journal of Gambling Studies 26(4): 503-520.

McMillen, J., L. Marshall, et al. (2004). The use of ATMs in ACT gambling venues: An empirical study.

Messerlian, C., J. Derevensky, et al. (2004). "A Public Health Perspective for Youth Gambling." International Gambling Studies 4(2): 147-160. 
Messerlian, C., J. Derevensky, et al. (2005). "Youth gambling problems: a public health perspective." Health Promotion International 20(1): 69-79.

Metcalfe, J. and W. Mischel (1999). "A hot/cool-system analysis of delay of gratification: dynamics of willpower." Psychol Rev 106(1): 3-19.

Mischel, W. and O. Ayduk (2004). Willpower in a cognitive-affective processing system. Handbook of Self-Regulation; Research, Theory, and Applications. R. F. Baumeister and K. D. Vohs. New York, The Guilford: 99-129.

Nower, L. and A. Blaszczynski (2004). A pathways approach to treating youth gamblers. Gambling Problems in Youth - Theoretical and Applied Perspectives. J. Derevensky and R. Gupta. New York, Kluwer Academic: 189-210.

O'Connor, J. and M. Dickerson (2003). "Definition and measurement of chasing in offcourse betting and gaming machine play." L Gambl Stud 19(4): 359-386.

Olason, D. T., E. Kristjansdottir, et al. (2011). "Internet Gambling and Problem Gambling Among 13 to 18 Year Old Adolescents in Iceland." International Journal of Mental Health and Addiction 9(3): 257-263.

Olason, D. T., K. Sigurdardottir, et al. (2006). "Prevalence estimates of gambling participation and problem gambling among 16-18-year-old students in Iceland: a comparison of the SOGS-RA and DSM-IV-MR-J." L Gambl Stud 22(1): 23-39.

Orford, J. (2001). "Addiction as excessive appetite." Addiction 96(1): 15-31.

Petry, N. (2006). "Should the scope of addictive behaviors be broadened to include pathological gambling?" Addiction 101 Suppl 1: 152-160.

Petry, N. (2010) Pathological Gambling and the DSM-V: Potential Impact on Adolescents. YGI NEwsletter 10, 1-2

Potenza, M. N., M. A. Steinberg, et al. (2006). "Characteristics of Older Adult Problem Gamblers Calling a Gambling Helpline." J Gambl Stud.

Poulin, C. (2000). "Problem gambling among adolescent students in the atlantic provinces of Canada." L Gambl Stud 16(1): 53-78.

Poulin, C. (2002). "An assessment of the validity and reliability of the SOGS-RA." L Gambl Stud 18(1): 67-93.

Proimos, J., R. H. DuRant, et al. (1998). "Gambling and other risk behaviors among 8th- to 12th-grade students." Pediatrics 102(2): e23.

Raylu, N. and T. P. Oei (2002). "Pathological gambling. A comprehensive review." Clin Psychol Rev 22(7): 1009-1061.

Rehm, J. (1999). "Draining the ocean to prevent shark attacks?" Nordic Studies on Alcohol and Drugs 16: 46-54. 
Romer, D. (2003). Prospects for an Integrated Approach to Adolescent Risk Reduction. Reducing Adolescent Risk, Toward an Integrated Approach. D. Romer. Thousand Oaks, California, Sage Publications, Inc.: 1-7.

Romer, D. (2003). Reducing adolescent risk: Toward an intergrated approach. Thousand Oaks, CA, Sage Publications.

Room, R., N. Turner, et al. (1999). "Community effects of the opening of the Niagara casino." Addiction 94(10): 1449-1466.

Rose, G. (1981). "Strategi of Prevention: Lessons from Cardiovascular Disease." British Medical Journal 282: 1847-1851.

Rose, G. (1985). "Sick individuals and sick populations." Int J Epidemiol 14(1): 32-38.

Rose, G. (1992). The Strategy of Preventive Medicine. Oxford, Oxford University Press.

Rose, G. and S. Day (1990). "The population mean predicts the number of deviant individuals." BMJ 301(6759): 1031-1034.

Rossow, I. (2010). "Challenges in an affluent society." Nordic Studies on Alcohol and Drugs 27(5): 449-463.

Rossow, I. and M. Hansen (2003). Underholdning med bismak : ungdom og pengespill / elektronisk ressurs. Oslo, Norsk institutt for forskning om oppvekst, velferd og aldring.

Rossow, I. and H. Molde (2006). "Chasing the criteria: comparing SOGS-RA and the $\mathrm{Lie} /$ Bet screen to assess prevalence of problem gambling and 'at-risk' gambling among adolescents." Journal of Gambling Issues (18).

Shaffer, H. J. and M. N. Hall (2001). "Updating and refining prevalence estimates of disordered gambling behaviour in the United States and Canada." Canadian Journal of Public Health-Revue Canadienne De Sante Publique 92(3): 168-172.

Shaffer, H. J., M. N. Hall, et al. (1999). "Estimating the prevalence of disordered gambling behavior in the United States and Canada: a research synthesis." Am J Public Health 89(9): 1369-1376.

Shaffer, H. J. and D. A. Korn (2002). "Gambling an related mental disorders: A public health analysis." Annual Review of Public Health 23: 171-212.

Sharpe, L. (2002). "A reformulated cognitive-behavioral model of problem gambling: A biopsychosocial perspective." Clinical Psychology Review 22(1): 1-25.

Sharpe, L., M. Walker, et al. (2005). "Structural changes to electronic gaming machines as effective harm minimization strategies for non-problem and problem gamblers." L Gambl Stud 21(4): 503-520.

Shinogle, J., D. F. Norris, et al. (2011). Gambling Prevalence in Maryland: A Baseline Analysis. Baltimore, University of Maryland. 
Skog, O. J. (1985). "The Collectivity of Drinking Cultures: A Theory of the Distribution of Alcohol Consumption.*." British Journal of Addiction 80(1): 83-99.

Skog, O. J. (1991a). Implikations of the Distribution Theory for Drinking and Alcoholism. Society, culture and drinking patterns re-examined. D. J. Pittmann and H. White. New Brunswick, NJ, Rutgers Center of Alcohol Studies: 576-597.

Skog, O. J. (1991b). Drinking and the distrubution of alcohol consumption. Society, culture, and drinking patterns re-examined. D. J. Pittmann and H. White. New Brunswick, NJ, Rutgers Center of Alcohol Studies: 135-156.

Skog, O. J. (2000). "Commentary on Gmel \& Rehm's interpretation of the theory of collectivity of drinking culture." Drug and Alcohol Review 20: 325-331.

Skog, O. J. (2006). "Alcohol and the so-called prevention paradox: how does it look today?" Addiction 101(2): 155-158.

Skog, O. J. and I. Rossow (2006). "Flux and stability: individual fluctuations, regression towards the mean and collective changes in alcohol consumption." Addiction 101(7): 959970 .

Skog, O. J. and I. Rossow (2006). "Flux and stability: individual fluctuations, regression towards the mean and collective changes in alcohol consumption." Addiction 101(7): 959970 .

Stinchfield, R. (2004). Demographic, Psychosocial, and Behavioral Factors Associated with Youth Gambling and Problem Gambling. Gambling problems in youths: Theoretical and applied perspectives. J. Derevensky and R. Gupta, Kluwer Academic/Plenum Publisher.

Stinchfield, R. (2010). "A critical review of adolescent problem gambling assessment instruments." Int J Adolesc Med Health 22(1): 77-93.

Stinchfield, R. (2011). "Gambling Among Minnesota Public School Students From 1992 to 2007: Declines in Youth Gambling." Psychology of Addictive Behaviors 25(1): 108-117.

Toneatto, T. and L. Nguyen (2007). Individual Characteristics and Problem Gambling Behavior. Research and Measurement Issues in Gambling Studies. G. Smith, D. C. Hodgins and R. J. Williams. London, Elsevier: 280-295.

Veerman, J. L., C. Dowrick, et al. (2009). "Population prevalence of depression and mean Beck Depression Inventory score." Br J Psychiatry 195(6): 516-519.

Volberg, R. (1993). Gambling and problem gambling among adolescents in Washington State. Report to the Washington State Lottery. Albany, NY, Gemini Research.

Volberg, R. (2003). Why pay attention to adolescent gambling? Reducing adolescent risk toward an integrated approach. D. Romer. London, Sage: 256-261.

Volberg, R., R. Gupta, et al. (2010). "An international perspective on youth gambling prevalence studies." Int J Adolesc Med Health 22(1): 3-38. 
Welte, J. W., G. M. Barnes, et al. (2008). "The prevalence of problem gambling among US Adolescents and young adults: Results from a national survey." Journal of Gambling Studies 24(2): 119-133.

Welte, J. W., G. M. Barnes, et al. (2009). "The association of form of gambling with problem gambling among American youth." Psychol Addict Behav 23(1): 105-112.

West, R. (2007). Theory of addiction. Oxford, Blackwell Publishing.

WHO (2009). ICD-10: International statistical classification of disieases and related health problems. W. H. Organization. Genava. 10th revision, 2008 edition.

WHO, I. A. f. R. o. C. (2009). Evaluating the effectiveness of smoke-free policies. IARC Handbooks of cancer prevention. Geneva. 13.

Williams, R. J., B. L. West, et al. (2007). Prevention of Problem Gambling: A

Comprehensive Review of the Evidence, Report prepared for the Ontario Problem

Gambling Research Centre, Guelph,

Ontario, CANADA.

Winters, K., C., R. Stinchfield, et al. (1995). "Monitoring adolescent gamlbing in Minnesota." Journal of Gambling Studies 11: 165-183.

Winters, K. C., R. Stinchfield, et al. (1993). "Toward the development of an adolescent gambling problem severity scale." Journal of Gambling Studies 9(1): 63-84. 



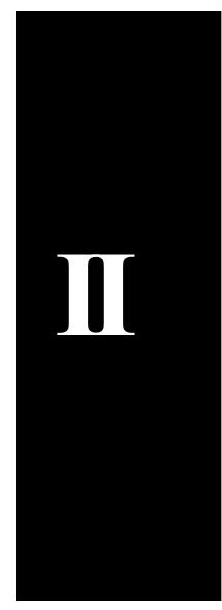





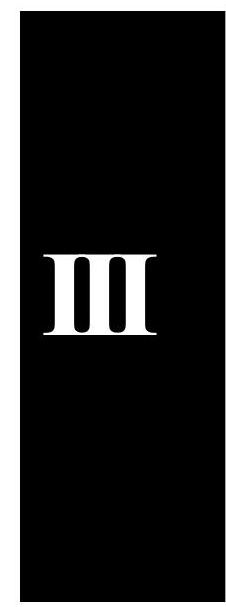



Running head: REDUCTION AT ALL LEVELS OF GAMBLING?

Does a reduction in the overall amount of gambling imply a reduction at all levels of gambling?

\section{Marianne B. Hansen}

Norwegian Institute for Alcohol and Drug Research, Oslo

$\&$

\section{Ingeborg Rossow}

Norwegian Institute for Alcohol and Drug Research, Oslo

Correspondence to:

Marianne Hansen

Norwegian Institute for Alcohol and Drug Research

POB 565 Sentrum, 0105 Oslo, Norway

E-mail:mh@sirus.no

Phone +4722340420

Fax: +4722340401

Conflict of interests: None declared

Total pages: 23

Word count: 5649

Date of submission: $28^{\text {th }}$ March 2011

Revised and resubmitted $30^{\text {th }}$ June 2011 


\begin{abstract}
The frequencies of slot machine gambling decreased in Norway after a major regulation in the slot machine market in 2006 . This study addressed whether a change in population gambling frequency mean is accompanied by a systematic displacement at all levels of gambling frequency among adolescents, across different population samples and over time in the same population. Data was collected in two cross-sectional school surveys among 13-19 year olds in Norway in 2005 and 2006. Net samples comprised 21202 and 20642 students, respectively. The students reported annual gambling frequency for six games for money, and a variable for total gambling frequency was analyzed. A strong regularity in the distribution of gambling behavior was observed and gambling at all levels, from light and moderate to frequent and excessive gambling, varied systematically with mean gambling frequency. Thus, a change in the population mean was accompanied by a systematic displacement at all levels of gambling behavior and not only at high to excessive levels of gambling. The findings are in line with those reported in other health areas and relevant to a public health perspective on problem gambling, suggesting that prevention strategies aimed at the total population of gamblers may affect also affect excessive gambling.
\end{abstract}

Keywords: Distribution; gambling frequency; percentile; public health; prevention; population; adolescent gambling; Norway 


\section{INTRODUCTION}

Problem gambling is a growing public health concern (Messerlian, Derevensky and Gupta 2005; Griffiths, Hayer and Meyer 2009; Adams, Raeburn and de Silva 2009). Problem gamblers may experience a wide array of negative consequences such as financial problems, strained relationships, criminal behavior and depression; consequences which have short-term and long-term implications for the individual, family and friends and for society at large (Messerlian et al. 2005). Also the determinants and risk factors for problem gambling are of many kinds and at different levels, such as individual characteristics, social network and interpersonal characteristics, and societal characteristics (Messerlian et al. 2005). Thus, the determinants and the consequences of problem gambling do not only pertain to individual gamblers but also to society as a whole. Therefore, several scholars in the field have advocated that gambling issues should be examined from a public health perspective (Shaffer and Korn 2002; Korn, Gibbins and Azmier 2003; Messerlian et al. 2005).

Chipman and co-workers (2006) have argued that in a public health approach to gambling problems the distribution of consumption model is highly relevant. This model, mostly referred to as 'the total consumption model' or 'the single distribution theory', stems from alcohol epidemiology and posits that there is a close association between total consumption and the prevalence of heavy drinkers in a population (Ledermann 1956, as cited in Skog 1985). Thus, empirical analyses from various populations have demonstrated that the higher the total alcohol consumption - or the mean consumption - in a population, the higher is the prevalence of heavy drinkers in that population, and vice versa (Skog 1985, 1991; Lemmens 1991). In the wake of Skog's (1985) work, Rose and Day (1990) found evidence for the validity of the total consumption model in a more general sense by also establishing a close association between the population mean and prevalence of morbidity in other health areas (i.e. blood pressure, weight and salt intake). They noted that "the population mean 
predicts the number of deviant individuals" and thus that "... the problem of the high risk deviant minority can be understood only when considered in the context of the whole population." Later studies have found that this main rule of Rose and Day also applies to depressive symptoms (Veerman, Dowrick, Ayuso-Mateos et al. 2009) and prescription psychotropic drug use (Bramness and Rossow 2010). The implications of the total consumption model for prevention are significant, as the model predicts that a reduction of the population mean will also imply a reduction in the prevalence of the problem in question (Rose and Day 1990).

Within gambling research, the total consumption model has, in various ways, been addressed in a few empirical studies (Room, Turner and Ialomiteanu 1999; Grun and McKeigue 2000; Chipman, Govoni and Roerecke 2006; Lund 2008; Hansen and Rossow 2008; Hansen and Rossow 2010). The study by Chipman and co-workers (2006) described the skewed distribution of gambling within a single population, whereas the studies by Lund (2008) and Hansen and Rossow (2008) demonstrated a close association between population mean and prevalence of problem gambling in various populations. The studies by Room and co-workers (1999), Grun and McKeigue (2000) and Hansen and Rossow (2010) are indicative of the total consumption model, as they all demonstrated that the level of gambling in the population and the prevalence of problem gambling changed in the same direction after a significant change in the availability of gambling. In other words, it seems that the higher the total (or average) gambling in a population, the higher is the prevalence of problem gamblers, and vice versa. Thus, there is some empirical evidence that the total consumption model also seems to apply to gambling and problem gambling.

In principle, the close association between the population mean and the prevalence of problems (e.g. gambling problems) can arise from two different mechanisms, which have different implications for prevention strategies. For the sake of simplicity, in the following we 
will refer to total gambling and prevalence/proportion of problem gamblers, although we assume a general applicability. First, the association may arise if problem gamblers systematically account for a large proportion of total gambling (whether measured as money spent on gambling, gambling frequency, time spent on gambling, or otherwise). If so, a change in the proportion of problem gamblers will necessarily imply a change in the population mean, even if the majority of gamblers do not change their behavior, and in that case high risk prevention strategies may be appropriate. Another - and more plausible mechanism is that of a strong regularity in the distribution of gambling behavior, implying that a change in the population mean is accompanied by a systematic displacement at all levels of gambling behavior, not only a change in the small group of problem gamblers. In such a case, population-based prevention strategies may be appropriate.

This latter mechanism is described in alcohol epidemiology and is well explained in Skog's theory of the collectivity of the drinking culture (Skog 1985). Here Skog showed that a change in mean alcohol consumption is accompanied by a change in consumption at all drinking levels; i.e. "the whole population move upwards along the consumption scale when the mean increases" (Skog 1985). In line with this, Rose and Day (1990) noted that "to the extent that population distributions shift up or down as a whole, retaining the same shape, then mean and prevalence will correlate".

Whether either of these mechanisms applies to gambling and problem gambling is not clear, but in this paper we will address the applicability of the latter; i.e. a strong regularity in the distribution of gambling behavior. There are two reasons for this. First, gambling and problem gambling seem to parallel those of alcohol consumption and heavy drinking in several ways (Korn et al. 2003; Chipman et al. 2006), among which a complex of individual and societal risk factors for the behavior seems particularly relevant in this respect. Second, if a shift in mean gambling is accompanied by a shift at all gambling levels, this is highly 
relevant in a public health perspective, in part with respect to the implications for population prevention strategies. So far, only a few studies have addressed this issue with respect to gambling. A recent literature search (in March 2011) in PubMed with the terms, 'gambling' and 'total consumption' retrieved 20 records. Of these, only three articles were relevant here (Grun and Mc Keigue 2000; Hansen and Rossow 2008; Lund 2008) In addition, a search in Google Scholar with the terms 'single distribution', 'gambling', and 'population'. retrieved 280 hits, but only one additional study of relevance here (Chipman et al. 2006). Among these, only one study (by Lund 2008) has demonstrated an association between population mean and distribution of gambling behavior; i.e. she found that the mean as well as the deciles of gambling frequency were systematically lower among female than among male gamblers. Hence, further empirical studies on this topic seem warranted.

In this paper we have focused on adolescent gambling. The growing public health concern with gambling appears to be more significant with respect to adolescents (Shaffer and Korn 2002; Messerlian et al. 2005). This probably reflects the fact that young people appear to be particularly vulnerable to the risks and negative consequences of gambling, and the prevalence rates of problem gambling are higher among adolescents (4-8\%) than in the general population (1-3\%) (Derevensky et al. 2003). Thus, strategies to prevent gambling problems are often targeted at young people or, in part, motivated by concern about gambling among young people. In Norway, gambling on slot machines was first regulated by the removal of bank note acceptors on all slot machines from July $1^{\text {st }} 2006$. Prior to this regulation slot machine gambling had increased tremendously over some years. The Norwegian authorities' decision to prohibit bank note acceptors on all slot machines was out of concern for gambling problems and in order to curb problems from slot machine gambling, also among adolescents. In the wake of this regulation, the average level of gambling 
behavior and the prevalence of problem gambling decreased among adolescents in Norway (Hansen and Rossow 2010).

In the present study we aimed at assessing whether the previously observed associations between population mean and prevalence of problems with respect to gambling can be explained by a strong regularity in the distribution of gambling behavior. More specifically, we have addressed whether there is a systematic displacement at all levels of gambling behavior with different mean values of gambling behavior among adolescents, across different population samples and over time within the same population.

\section{METHODS}

Participants and procedures

The present study is based on data from Norwegian school surveys conducted in the same municipalities and schools at two time points; in 2005 and 2006. The school surveys were conducted in October/November each year as a joint data collection for two different evaluation projects, of which one was to assess possible effects of national efforts on regulating the slot machine market. The first school survey was conducted prior to the removal of bank note acceptors, in 2005. The second school survey was conducted approximately four months after the removal of bank note acceptors in 2006.

The target population comprised all students in grades 8 through 13 (mainly age 13-19 years) in 16 municipalities in Norway. Through a letter of invitation to each school all students in that school were invited to participate in the surveys. Students in senior high school were included both from academic and vocational training. The questionnaire was completed at school. A written informed parental consent was obtained for students in grades 8 through 10, whereas a passive informed parental consent was obtained for students below 18 years in grades 11 through 13. More information about procedures and data collection is 
described in detail in Pape et al. (2007). Net samples comprised 21202 in 2005 and 20642 in 2006, and the response rates were $86.7 \%$ (2005) and $85.7 \%$ (2006), respectively. The response rate is calculated on the basis of all students in the selected schools. Some of the non-response was could be ascribed that whole school classes were absent at the time of the data collection, for instance due to school trips and extra-mural vocational training, whereas obtaining parental consent did not affect the response rates. Average age was 15.5 years and $50.1 \%$ were girls. The analyses are based on data from the respondents who had gambled for money during the last 12 months, and these sub-samples comprised 14458 and 13387 respondents in 2005 and 2006, respectively.

\section{Measures}

We have used gambling frequency as a measure of gambling behavior. This has previously been done in several studies (see Lund, 2008 for a review) and seems to be a good approximation to gambling volume. Gambling frequency in the preceding 12 months was assessed for six categories of games; slot machines, scratch cards, internet gambling, horse racing, sports betting and lotteries, and 'other forms of gambling'. There were six response categories: 'Not gambled last year', 'Less than once a month', 'Several times a month', 'Once a week', 'Several times a week' and 'Daily or almost daily'.

In order to construct a sum-score for overall gambling frequency we applied a semicontinuous measure reflecting (approximate) number of times gambled in the past year (i.e. 0 , $10,25,52,100$ and 220, respectively) for each category of gaming. Then these semicontinuous variables could be added into a sum-score which could be used for descriptive statistical purposes, e.g. means and percentiles. This sum-score indicating total gambling frequency in the past year had values ranging from $0-1320$. Values above 900 were considered as less trustworthy and were therefore coded as missing ( $\mathrm{n}=190$ in 2005 and 
$\mathrm{n}=185$ in 2006). Internet gambling frequency was assessed somewhat differently in 2006 compared to 2005 because poker gambling on the Internet had gained increasing popularity among young people at that time. Thus, whereas the students in the 2005 survey were asked one question about how often they gambled on the Internet, two questions on internet gambling frequency were asked in 2006; one pertaining to poker and another to other forms of internet gambling. A mean score of these two variables in 2006 was applied in order to obtain comparable measures over time.

Parallel to Skog's categorization of prototypical drinkers (Skog 1985), we applied four categories of prototypical gamblers based on their levels of gambling frequency; 1) light to moderate gamblers (below the $50^{\text {th }}$ percentile; i.e. the $50 \%$ who gambled least frequently); 2) frequent gamblers (above the $75^{\text {th }}$ percentile; i.e. the $25 \%$ who gambled most frequently); 3) very frequent gamblers (above the $90^{\text {th }}$ percentile; i.e. the $10 \%$ who gambled most frequently); and 4) excessive gamblers (above the $95^{\text {th }}$ percentile; i.e. the $5 \%$ who gambled most frequently). Differences in distributions at the lower levels of gambling frequency could not be obtained, as more than 30 percent of the adolescents had a score of 10 , which was the least possible value on the total gambling frequency variable.

Statistical analysis and strategy of analysis

Gambling frequency for all games was compared for 2005 and 2006. Differences in mean values for the total gambling frequency variable between various groups of gamblers and between survey years were tested by analysis of variance (ANOVA) and F-tests.

In order to assess whether a difference in mean gambling frequency was associated with a systematic displacement at all levels of gambling, we first examined how the four percentiles; the $50^{\text {th }}$, the $75^{\text {th }}$, the $90^{\text {th }}$ and the $95^{\text {th }}$ percentiles were related to the mean. This was done for each survey year for the total sample of gamblers and for boys and girls 
separately, and the figures presented in a table. In addition, we assessed also these distribution measures for 8 groups of senior high school students (divided by survey year, gender and study program at school) ( $\mathrm{n}=14$ 392) so as to obtain a larger number of groups to compare. Groups with almost the same mean values were treated as one, and this applied to two pairs of groups. Thus, we obtained six sub-groups with different mean values on the gambling frequency score, and the mean values varied between 24 and 84 . The four percentile values $\left(50^{\text {th }}, 75^{\text {th }}, 90^{\text {th }}\right.$ and $\left.95^{\text {th }}\right)$ were graphically plotted against the mean values for these six subgroups.

Moreover, we wanted to test whether displacements at each level of gambling from 2005 to 2006 were statistically significant. This was done by testing the differences in the proportion of gamblers above a certain cut-off value of gambling frequency within each of the four levels of gambling and for each of the two survey years. For example, we tested whether the level of frequent gamblers (above the $75^{\text {th }}$ percentile) was statistically significantly lower in 2006 than in 2005 by comparing the proportion who had a gambling frequency score above 80 among frequent gamblers (above the $75^{\text {th }}$ percentile) in 2005 and in 2006 . A Pearson's chi square test was applied to assess whether the proportions were statistically significantly different. These analyses were conducted for each survey year for all gamblers and for male and female gamblers separately.

\section{RESULTS}

The distribution of gambling frequency was very skewed; whereas three out of four gamblers gambled below the mean gambling frequency, the mean was 2.4 times higher than the median and $11.3 \%$ of the gamblers had a gambling frequency score above two times the average. The distribution of the total gambling frequency score displayed a clear regularity across subpopulations. As can be seen in Table 1 and Figure 1 , the $50^{\text {th }}, 75^{\text {th }}, 90^{\text {th }}$ and $95^{\text {th }}$ percentiles 
varied systematically with the mean values across sub-populations; the higher the mean value the higher were these percentile values. Moreover, in sub-populations with higher mean values the absolute dispersion was larger.

Table 1 about here

Figure 1 about here

Table 2 shows that at each level of gambling (e.g. frequent gamblers, excessive gamblers). the proportion who had a gambling frequency score above a certain value decreased statistically significantly from 2005 to 2006, in parallel to the decrease in mean gambling frequency. For instance, among the 50 percent who had gambled least, (below the $50^{\text {th }}$ percentile) in 2005 , 41.3 percent had gambled more than 20 times last year, whereas the corresponding proportion in 2006 was 38.7 percent. This difference was statistically different $\left(\chi^{2}=10.87, p<0.001\right)$. Likewise, among the 5 percent who gambled most frequently (above the $95^{\text {th }}$ percentile) in 2005, virtually all (98.9 percent) had gambled more than 200 times last year, whereas the corresponding proportion in 2006 was 89.6 percent $\left(\chi^{2}=58.08, p<0.001\right)$.

Table 2 about here 
Corresponding analyses were also conducted for boys and girls separately, as gambling frequency distribution differed by gender, and gambling frequency was more than twice as high for boys compared to girls in both survey years. However, the results displayed the same pattern for both male and female gamblers; with the decrease in mean gambling frequency from 2005 to 2006, a collective downward shift in gambling frequency at all levels could be observed.

Table 3 about here

\section{Sensitivity analyses}

In the total gambling frequency measure applied in the analyses presented above, values above 900 had been excluded and somewhat different measures of internet gambling in the two surveys were included. In order to check whether this could be of any importance for the results, all analyses were re-run applying a frequency measure that also included values above 900 and a frequency measure where internet gambling was not included. The results of these analyses did not alter the overall picture; the same pattern was evident irrespective of whether internet gambling frequency was included or excluded in the analyses, and whether gambling frequency values above 900 were included or not. Moreover, the cut-off values applied in the analyses presented in Tables 2 and 3 were somewhat arbitrary. Thus, we have re-run these analyses applying different cut-off values at each gambling level, but the overall picture remained the same. Hence, the results appear to be fairly robust. 


\section{DISCUSSION}

This study has demonstrated that gambling frequency at all levels of gambling is sensitive to decreases in the mean gambling frequency in the Norwegian population of young people. We found a systematic displacement at all levels for gambling behaviour with different mean values for gambling behaviour. This was evident across different population samples with different means, and over time with a decreasing mean. In other words, a decrease in average gambling frequency was associated with a decrease in gambling frequency among excessive gamblers and the light to moderate gamblers.

Our findings of a skewed distribution of gambling frequency are in line with those reported in some previous studies (Chipman et al. 2006; Hansen and Rossow 2008; Lund 2008) and a significant association between mean gambling frequency and the proportion of problem gamblers or very frequent gamblers has also been demonstrated in a few previous studies (Room et al. 1999; Grun and McKeigue 2000; Lund 2008; Hansen and Rossow 2008). Correspondingly, Abott (2006) showed that prevalence of pathological gambling tended to be positively correlated with availability of gambling machines in Australia, New Zealand and Canada. As far as we know, only one previous study has addressed the regularity of the distribution of gambling behaviour (Lund 2008). In the present study we have taken this a bit further in two ways: we have compared distribution measures across a larger number of samples and we have compared distribution measures over time within the same population. Given the similarities between gambling and gambling problems on the one hand and drinking and heavy drinking on the other, it is noteworthy that our results mirror those previously reported on the distribution of alcohol consumption (Skog 1985; 1991; Lemmens 1991). In both respects the distribution is strongly skewed to the right and a change in the population mean implies parallel changes at all consumption levels. 
In Skog's work on the collectivity of drinking cultures (1985), he offered a theoretical framework (supported by empirical evidence) as to how the strong regularity in the distribution of alcohol consumption can be explained. However, this framework will not necessarily apply also to gambling behavior. Skog (1985) postulated two assumptions for the observed regularity in the distribution patterns of alcohol; - 1) the factors that influence people's drinking behavior tend to combine multiplicatively, and 2) an individual's drinking habits are strongly influenced by the drinking habits, attitudes and expectations in his or her personal social network. The question whether these assumptions may be valid with respect to gambling behavior is therefore of obvious relevance. Although it is clear that there are many determinants and risk factors for gambling and problem gambling, both at the individual level and at the societal level (Messerlian et al. 2005), it is not clear whether these combine multiplicatively. Neither do we know much about the importance of social interaction and social influences on gambling behavior. Therefore, a closer examination of whether these assumptions may also be valid in the field of gambling and problem gambling will be valuable in order to explain the observed strong regularity in the distribution of gambling behavior.

\section{Strengths and limitations}

This study was based on exceptionally large survey samples with identical data collection procedures and almost identical instruments in two data collection waves 12 months apart. This provided a unique opportunity to obtain several comparable sub-samples of sufficient sample size to assess small categories of gamblers (e.g. those above the $95^{\text {th }}$ percentile). An alternative approach could have been to compare distributions of gambling behaviour in various studies and samples with different sample means, but that would have required comparable measures of gambling behaviour across studies. The fairly high response rates no 
only suggest that the target population is fairly well captured, but have probably contributed to a better representation of frequent and excessive gamblers and thus a larger dispersion of gambling frequency than what could be expected if the response rates had been lower. Yet, the finding of a strong regularity in the distribution of gambling behaviour is probably not dependent on a very high response rate.

Some study limitations should be noted. First, as there was only one response category for infrequent gambling (i.e. less than monthly) for each type of gambling and it appeared that a fairly large proportion of Norwegian adolescents seems to gamble infrequently, the total gambling frequency measure was crude in the lower part of the scale. This implied that we could not assess whether the 'very light gamblers' (e.g. below the $25^{\text {th }}$ percentile) also changed systematically with a change in mean value in line with the other categories of prototypical gamblers. Second, we applied only one measure of gambling behavior; i.e. gambling frequency, which is just one of several aspects of gambling behavior and we do not know whether our results may also apply to other aspect of gambling behavior such as time and money spent on gambling. Finally, this study is based on data from adolescent and thus we do not know whether these results apply to the general population, even though the findings reported by Lund (2008) may point in that direction.

Implications for prevention and further research

Our findings are very much in line with those of Rose and Day (1990), who concluded that; the close link between mean and prevalence implies that to help the minority; the "normal" majority must change. In the context of gambling problems, this would imply that in order to reduce excessive gambling in a population, the majority of gamblers must also reduce their gambling. In this respect prevention strategies directed at the total population of gamblers seem highly relevant if they are effective in reducing overall gambling. Our findings suggest 
that a downward shift in gambling behavior in the population may reduce gambling problems in two ways. First, it will imply a reduction in prevalence of excessive gamblers and a reduction in gambling behavior among the most heavy gamblers. Indeed, this is also in line with our finding that a restriction in availability (i.e. the removal of note acceptors on slot machines in Norway) was followed by a reduction in gambling frequency and in problem gambling among Norwegian adolescents. Second, a downward shift in gambling behavior in the population will also imply a reduction in the proportion of at-risk gamblers, who may constitute a recruitment pool for problem gambling, and thus this may indirectly - in the longer run - contribute to preventing problem gambling.

Except from the current study and the study by Lund (2008), there is little knowledge about the relationship between the mean and the gambling level of various groups of gamblers. Particularly in view of the significant implications for prevention strategies, replications of this study are therefore clearly warranted. A suggestion for future research would be to examine this relationship by applying data from various countries and cultures. However, this would require that gambling behavior is measured in compatible ways across surveys. Further, more research is certainly needed to improve our understanding of the determinants of the population level of gambling frequency. In line with Rose's arguments (1992), we argue that it is important to not only address individual characteristics and features of the small minority of problem gamblers, but also the characteristics of societies in which the incidence and prevalence of problem gambling are high. 


\section{REFERENCES}

Abbott, M. (2006). Do EGMs and Problem Gambling go together like a Horse and Carriage? Gambling Research: Journal of the National Association fo Gambling Studies (Australia), 18, 7-38.

Adams, P. J., Raeburn, J., \& de Silva, K. (2009). A question of balance: prioritizing public health responses to harm from gambling. Addiction, 104, 688-691.

Bramness, J. G., \& Rossow, I. (2010). Can the total consumption of a medicinal drug be used as an indicator of excessive use? The case of carisoprodol. Drugs: education, prevention and policy, 17(2), 168-180.

Chipman, M. L., Govoni, R., Roerecke, M. (2006). The distribution of consumption model: an evaluation of its applicability to gambling behaviour. Ontario Problem Gambling Centre, Guelph, Ont.

Derevensky, J., Gupta, R., \& Winters, K. (2003). Prevalence Rates of Youth Gambling Problems: Are the Current Rates Inflated? Journal of Gambling Studies, 19,(4), 405425.

Griffiths, M., Hayer, T., \& Meyer, G. (2009). Problem Gambling: A European Perspective. In G. Meyer, T. Hayer \& M. Griffiths (Eds.). Problem Gambling in Europe - Challenges, Prevention, and Interventions. Springer, New York.

Grun, L., \& McKeigue, P. (2000). Prevalence of excessive gambling before and after introduction of a national lottery in the United Kingdom: Another example of the single distribution theory. Addiction, 95(6), 959-966.

Hansen, M., \& Rossow, I. (2008). Adolescent gambling and problem gambling: Does the total consumption model apply? Journal of Gambling Studies, 24, 135-149.

Hansen, M., \& Rossow, I. (2010). Limited cash flow on slot machines: Effects of 
prohibition of note acceptors on adolescent gambling behavior. International Journal of Mental Health and Addiction, 8, 70-81.

Korn, D. A., Gibbins, R., \& Azmier, J. (2003). Framing public policy towards a public health paradigm for gambling. Journal of Gambling Studies, 19(2), 235-256.

Lemmens, P. (1991). Measurement and distribution of alcohol consumption. Dissertation Maastrict, Netherlands.

Lund, I. (2008). The population mean and the proportion of frequent gamblers: Is the theory of total consumption valid for gambling? Journal of Gambling Studies, 24, 247 256.

Messerlian, C., Derevensky, J. \& Gupta, R. (2005). Youth gambling problems: a public health perspective. Health Promotion International, 20(1), 69-79.

Pape, H., Rossow, I., \& Storvoll, E. E. (2007). Report of study methodology for the school surveys 2004, 2005 and 2006 for evaluation of the Regional project carried out by the Norwegian Institute for Alcohol and Drug Research. Oslo: Norwegian Institute for Alcohol and Drug Research. Retrieved January $11^{\text {th }} 2011$ from: http://burns.idium.no/sirus.no/filestore/Import_vedlegg/metoderapport_engelsk_region prosj.pdf

Room, R., Turner, N. E., \& Ialomiteanu, A. (1999). Community effects of the opening of the Niagara casino. Addiction, 94(10), 1449-1466.

Rose, G. (1992). The strategy of preventive medicine. Oxford University Press, NY; Oxford Medical Publications.

Rose, G., \& Day, S. (1990). The population mean predicts the number of deviant individuals. Brithsh Medical Journal, 301, 1031-1034.

Shaffer, H. J., \& Korn, D. A. (2002). Gambling and related mental disorders: A Public Health Analysis. Annual Review of Public Health, 23, 171-212. 
Skog, O. J. (1985). The Collectivity of Drinking Cultures: A theory of the Distribution of Alcohol Consumption. British Journal of Addiction, 80, 83-99.

Skog, O. J. (1991). Implications of the Distribution Theory for Drinking and Alcoholism. In D. J. Pittman, \& H. White (Eds.), Society, culture, and drinking patterns re-examined (pp. 576-597). Rutgers Center of Alcohol Studies, New Brunswick, USA.

Veerman, J. L., Dowrick, C., Ayuso-Mateos, J. L., Dunn, G., \& Barendregt, J. J. (2009). Population prevalence of depression and mean Beck Depression Inventory score. The British Journal of Psychiatry, 195, 516-519. 
Figure 1 Relationship between average gambling frequency and the gambling frequency level of selected gambling groups (defined by percentiles) among Adolescent Gamblers

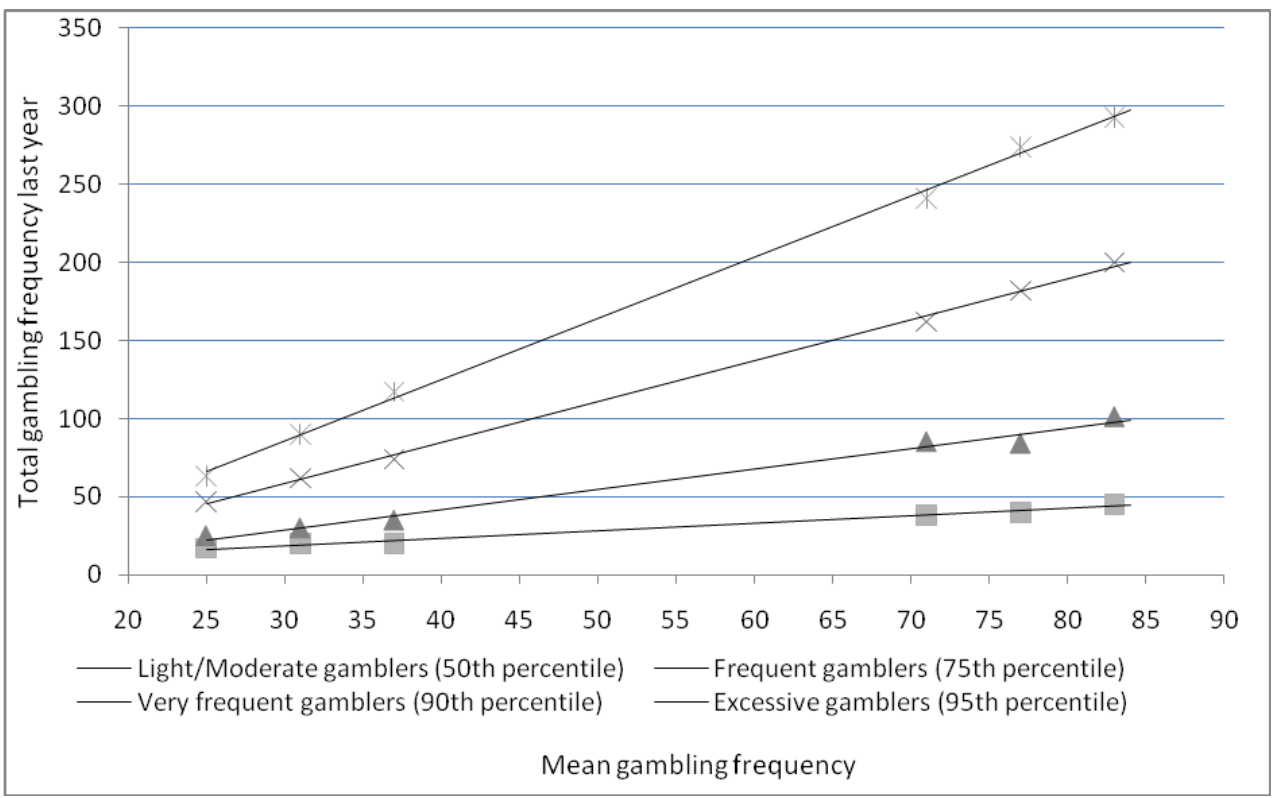


Table 1 Measures of distribution of total gambling frequency by survey year and gender

\begin{tabular}{ccc|cc|cc}
\hline & \multicolumn{2}{c|}{ All } & \multicolumn{2}{c|}{ Boys } & \multicolumn{2}{c}{ Girls } \\
& 2005 & 2006 & 2005 & 2006 & 2005 & 2006 \\
& $\mathrm{n}=14,458$ & $\mathrm{n}=13,387$ & $\mathrm{n}=7,874$ & $\mathrm{n}=7,281$ & $\mathrm{n}=6,565$ & $\mathrm{n}=6,035$ \\
\hline $\begin{array}{l}\text { Number of times gambled last year } \\
\text { (mean): }\end{array}$ & 52 & $48^{* * *}$ & 72 & $66^{* * *}$ & 28 & $25^{* * *}$ \\
$\mathbf{5 0}^{\text {th percentile }}$ & 20 & 20 & 35 & 30 & 20 & 10 \\
$\mathbf{7 5}^{\text {th percentile }}$ & 55 & 50 & 77 & 72 & 30 & 20 \\
$\mathbf{9 0}^{\text {th percentile }}$ & 120 & 110 & 166 & 152 & 55 & 50 \\
$\mathbf{9 5}^{\text {th percentile }}$ & 197 & 176 & 252 & 245 & 77 & 72 \\
\hline
\end{tabular}


Table 2 Proportion of adolescents gambling above certain levels by year and within groups of gamblers

2005

$\begin{array}{ccc}41.3 \% & 38.7 \% & \chi^{2}=10.87^{* * *} \\ (\mathrm{n}=3.250) & (\mathrm{n}=3.087) & \mathrm{df}=1\end{array}$

\section{Frequent gamblers}

Proportion above 80

Very frequent gamblers

Proportion above 150

Excessive gamblers

Proportion above 200

\section{$62.4 \%$} $(\mathrm{n}=2.300)$

$$
76.2 \%
$$

$98.9 \%$

$(n=722)$
$53.7 \%$

$\chi^{2}=54.86^{* * *}$ $\mathrm{df}=1$

Statistical test of difference from 2005 to 2006

$\begin{array}{cc}63.5 \% & \chi^{2}=53.96^{* * *} \\ (\mathrm{n}=852) & \mathrm{df}=1\end{array}$

$(\mathrm{n}=1.810)$

${ }^{* * *}=\mathrm{p}<0.001$

(a) Light gamblers $=$ gamble below the $50^{\text {th }}$ percentile on gambling frequency. Cut off value $>20$ times last year

(b) Moderate gamblers $=$ gamble above the $75^{\text {th }}$ percentile on gambling frequency. Cut off value $>80$ times last year

(c) Frequent gamblers $=$ gamble above the $90^{\text {th }}$ percentile on gambling frequency. Cut off value $>150$ times last year

(d) Excessive gamblers $=$ gamble above the $95^{\text {th }}$ percentile on gambling frequency. Cut off value $>200$ times last year 
Table 3 Proportion of boys and girls gambling above certain levels by year and within groups of gamblers. Percent.

\begin{tabular}{|c|c|c|c|}
\hline Boys & 2005 & 2006 & $\begin{array}{c}\text { Statistical test of } \\
\text { difference from } 2005 \text { to } \\
2006\end{array}$ \\
\hline Light to moderate gamblers & $24.4 \%$ & 14.0 & $\chi^{2}=134.38^{* * *}$ \\
\hline Proportion above 30 (1a) & $(\mathrm{n}=986)$ & $(\mathrm{n}=530)$ & $\mathrm{df}=1$ \\
\hline Frequent gamblers & $81.3 \%$ & $69.4 \%$ & $\chi^{2}=75.91^{* * *}$ \\
\hline Proportion above $100(2 a)$ & $(\mathrm{n}=1.653)$ & $(\mathrm{n}=1.325)$ & $\mathrm{df}=1$ \\
\hline $\begin{array}{l}\text { Very frequent gamblers } \\
\text { Proportion above } 200 \text { (3a) }\end{array}$ & $\begin{array}{c}80.2 \% \\
(\mathrm{n}=639)\end{array}$ & $\begin{array}{c}71.4 \% \\
(\mathrm{n}=534)\end{array}$ & $\begin{array}{c}\chi^{2}=16.29^{* * *} \\
\mathrm{df}=1\end{array}$ \\
\hline Excessive gamblers & $76.8 \%$ & $69.1 \%$ & $\chi^{2}=5.75^{*}$ \\
\hline Proportion above $300(4 a)$ & $(\mathrm{n}=302)$ & $(\mathrm{n}=253)$ & $\mathrm{df}=1$ \\
\hline \multicolumn{4}{|l|}{ Girls } \\
\hline Light to moderate gamblers & $37.3 \%$ & $32.0 \%$ & $\chi^{2}=28.04^{* * *}$ \\
\hline Proportion above 20 (1b) & $(\mathrm{n}=1.791)$ & $(\mathrm{n}=1.460)$ & $\mathrm{df}=1$ \\
\hline Frequent gamblers & $46.9 \%$ & $21.1 \%$ & $\chi^{2}=342.22^{* * *}$ \\
\hline Proportion above $50(2 \mathrm{~b})$ & $(\mathrm{n}=824)$ & $(\mathrm{n}=621)$ & $\mathrm{df}=1$ \\
\hline Very frequent gamblers & $48.2 \%$ & $35.3 \%$ & $\chi^{2}=22.36^{* * *}$ \\
\hline Proportion above $80(3 b)$ & $(\mathrm{n}=327)$ & $(\mathrm{n}=219)$ & $\mathrm{df}=1$ \\
\hline Excessive gamblers & $74.8 \%$ & $53.1 \%$ & $\chi^{2}=34.39^{* * *}$ \\
\hline Proportion above $100(4 b)$ & $(\mathrm{n}=255)$ & $(\mathrm{n}=178)$ & $\mathrm{df}=1$ \\
\hline
\end{tabular}

ns $=$ not significant, $* * *=\mathrm{p}<0.001$

Boys:

(1a) Light gamblers $=$ gamble below the 50thy percentile on gambling frequency. Cut off value $>30$ times last year

(2a) Moderate gamblers $=$ gamble above the $75^{\text {th }}$ percentile on gambling frequency. Cut off value $>100$ times last year

(3a) Frequent gamblers $=$ gamble above the $90^{\text {th }}$ percentile on gambling frequency. Cut off value $>200$ times last year

(4a) Excessive gamblers $=$ gamble above the $95^{\text {th }}$ percentile on gambling frequency. Cut off value $>300$ times last year

Girls:

(1b) Light gamblers $=$ gamble below the 50thy percentile on gambling frequency. Cut off value $>20$ times last year

(2b) Moderate gamblers $=$ gamble above the $75^{\text {th }}$ percentile on gambling frequency. Cut off value $>50$ times last year

(3b) Frequent gamblers $=$ gamble above the $90^{\text {th }}$ percentile on gambling frequency. Cut off value $>80$ times last year

(4b) Excessive gamblers $=$ gamble above the $95^{\text {th }}$ percentile on gambling frequency. Cut off value $>100$ times last year 



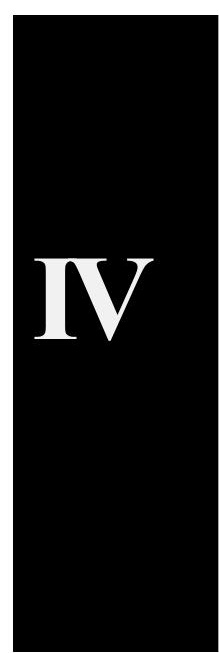


